Pablo Seguel, La organización de la represión y la inteligencia en la dictadura militar chilena. Del copamiento militar del territorio al surgimiento de la Dirección de Inteligencia Nacional: Región Metropolitana, 1973-1977, Izquierdas, 49, abril 2020:767-796

La organización de la represión y la inteligencia en la dictadura militar chilena. Del copamiento militar del territorio al surgimiento de la Dirección de Inteligencia Nacional: Región Metropolitana, 1973-1977

The organization of repression and intelligence in the Chilean military dictatorship. From the military takeover of the territory to the emergence of the National Intelligence Directorate: Metropolitan Region, 1973-1977

Pablo Seguel Gutiérrez*

Resumen: La emergencia de los antecedentes organizacionales de la DINA desde octubre de 1973, marcaron una ruptura en el desarrollo de las labores represivas y de inteligencia implementadas por las fuerzas armadas y policiales, pasando de una organización basada en el copamiento militar del territorio al desarrollo de una basada en criterios de inteligencia estratégica. En este artículo se describen y analizan los cambios organizacionales adoptados por la DINA en ese proceso, que la caracterizan como un servicio secreto de inteligencia política que se constituyó en una organización estatal y paraestatal. Para ello combinó repertorios legales e ilegales de acción, una estructura compartimentada, altamente jerarquizada y hermética que le permitió desarrollar de manera sistemática el terrorismo de Estado con fines de consolidar la dictadura militar.

Palabras clave: Represión, Inteligencia, violencia Estatal, Dirección de Inteligencia Nacional.

\begin{abstract}
The emergence of the organizational background of the DINA since October 1973, made a difference in the development of repressive and intelligence practices implemented by the military and police forces, changing from an organization based on the territorial military control to a development of strategic intelligence criteria. This paper describes and analyses the organizational changes adopted by the DINA in this process, which characterize it as a secret political intelligence service that became a state and parastatal organization. For these reasons, they mixed legal and illegal repertories of action and a compartmentalized, hermetic and highly hierarchical structure organization that allowed them to systematically develop state terrorism in order to consolidate the military dictatorship.
\end{abstract}

Keywords: repression, intelligence, State violence, Dirección de Inteligencia Nacional.

Recibido: 7 enero 2019 Aceptado: 8 abril 2019

\footnotetext{
* Chileno. Historiador y Licenciado en Sociología, Universidad de Chile. Estudiante de Magíster en Historia, Universidad Santiago de Chile. Becario CONICY'T Magíster Nacional 2018-2019 folio No 22180599. La idea central de este artículo fue presentada en las IX Jornadas de Historia Reciente, efectuada en la ciudad de Córdoba en 2018 y forma parte de la tesis de magíster. La participación en dicha jornada contó con el patrocinio del Departamento de Historia de la Universidad Santiago de Chile. Contacto: bseguelg@gmail.com
} 
Pablo Seguel, La organización de la represión y la inteligencia en la dictadura militar chilena. Del copamiento militar del territorio al surgimiento de la Dirección de Inteligencia Nacional: Región Metropolitana, 1973-1977, Izquierdas, 49, abril 2020:767-796

\section{La investigación de la represión en la historia reciente}

En los últimos años, el desarrollo historiográfico sobre la historia reciente en el cono sur ${ }^{1}$ ha generado una serie de investigaciones que han cuestionado los límites taxativos entre democracia y dictadura en relación al desarrollo de los dispositivos represivos, el ejercicio de la violencia estatal, paraestatal y las violaciones a los derechos humanos efectuadas por agentes de Estado y civiles amparados por el mismo². Específicamente los aportes de la Red de Estudios sobre Represión y Violencia Política al interior de esta corriente historiográfica han contribuido a la investigación desde el punto de vista de las instituciones, dispositivos y actores involucrados, colocando el énfasis en las prácticas y en la racionalidad de estas ${ }^{3}$. Desde esta óptica, el desarrollo de diversos estudios de caso, nuevos tratamientos metodológicos a los archivos e información producida por los tribunales de justicia y las comisiones de verdad y reconciliación han permitido avanzar en un análisis crítico de la represión 4 .

En términos generales, esto ha permitido evidenciar fuertes líneas de continuidad en el uso de dispositivos y mecanismos represivos por los diversos regímenes políticos, dando cuenta del rol coadyuvante del sistema político y del poder judicial en el desarrollo de la violencia (para) estatal y de las violaciones a los derechos humanos ${ }^{5}$. Esto ha evidenciado la convergencia en el discurso de seguridad nacional, de elementos propios de los discursos conservadores y militares, configurados en torno a la noción de enemigo interno y la construcción del imaginario anticomunista, motivo por el que estos estudios han permitido remarcar los componentes civiles y políticos fraguados a lo largo del siglo XX en este discurso militar ${ }^{6}$. Finalmente, esto ha posibilitado cuestionar el carácter excepcional de las

\footnotetext{
${ }^{1}$ En torno al campo de la historia reciente: Marina Franco y Florencia Levin, "El pasado cercano en calve historiográfica", Marina Franco y Florencia Levin (comp.), Historia reciente. Perspectivas y desafios para un campo en construcción, Buenos Aires, Paidós, 2006, pp. 31-65. Florencia Levin, "Escrituras de lo cercano. Apuntes para una teoría de la historia reciente Argentina", Nuevo Mundo Mundos Nuevos, 2018. Marina Franco, "La historiografía del tiempo presente en el cono sur", Gabriela Águila, Laura Luciani, Luciana Seminara y Cristina Viano (comps.), La historia reciente en Argentina. Balances de una historiografía pionera en América Latina, Buenos Aires, Imago Mundi, 2018, pp. 175-196. Patricia Flier (comp.), Dilemas, apuestas y reflexiones teórico-metodológicas para los abordajes en Historia Reciente. La Plata, Universidad Nacional de La Plata, 2014.

2 Marina Franco, Un enemigo para la nación. Orden Interno, violencia y "subversión", 1973-1976, Buenos Aires, Fondo de Cultura Económica, 2012. Ariel Eidelman, "La actividad paraestatal en la Argentina a principio de los años setenta", En Débora D’Antonio (comp.), Violencia, espionaje y represión estatal, Buenos Aires: Imago Mundi, 2018, pp. 27-58.

${ }^{3}$ Gabriela Águila, "La represión en la historia reciente argentina: fases, dispositivos y dinámicas regionales", Gabriela Águila y Luciano Alonso (comp.), Procesos represivos y actitudes sociales: entre la España franquista y las dictaduras del Cono Sur, Buenos Aires, Prometeo, 2013, pp. 97-121. Gabriela Águila, "La represión en la Historia Reciente Argentina: perspectivas de abordaje, conceptualizaciones y matrices explicativas", Contenciosa, año 1, no. 1, pp. 2-14. Gabriela Águila, "Estudiar la represión: entre la historia, la memoria y la justicia. Problemas de conceptualización y método", Patricia Flier (comp.), Dilemas, apuestas y reflexiones teórico-metodológicas para los abordajes en Historia Reciente, La Plata, Universidad Nacional de La Plata, pp. 20-55. Gabriela Águila, "La represión en la historia reciente como objeto de estudio: problemas, novedades y derivas historiográficas", Gabriela Águila, Laura Luciani, Luciana Seminara y Cristina Viano (comps.), La bistoria reciente en Argentina. Balances de una bistoriografia pionera en América Latina, Buenos Aires, Imago Mundi, 2018, pp. 55-72.

4 Varios autores, El batallón de inteligencia 601, Buenos Aires, Programa Verdad y Justicia Ministerio de Justicia y Derechos Humanos, 2015. Ariel Eidelman, El desarrollo de los aparatos represivos del Estado argentino durante la «Revolución Argentina», 1966-1973, Tesis doctoral, Buenos Aires, Universidad de Buenos Aires, 2010. Melisa Slatman, “«En la Argentina no había escuadrones de la muerte». El dispositivo represivo argentino, la responsabilidad primaria del ejército y la planificación centralizada-ejecución descentralizada (1975-1983)", Débora D’Antonio (comp.), Violencia, espionaje y represión estatal, Buenos Aires, Imago Mundi, 2018, pp. 119-139. Natalia Casola, "La creación de la Escuela de Inteligencia Policial Héctor Ramos. La policía política entre la dictadura y la transición democrática", Débora D’Antonio (comp.). Violencia, espionaje y represión estatal, Buenos Aires, Imago Mundi, 2018, pp. 141-163. Emmanuel Kahan, Unos pocos peligros sensatos. La Dirección de Inteligencia de a Provincia de Buenos Aires ante las instituciones judías de La Plata, Buenos Aires, Edulp, 2008.

5 Santiago Garaño, "Pabellones de la muerte: los límites difusos entre la represión legal y la clandestina", Revista Entrepasados, 34, pp. 33-53. María José Sarrabayrouse, "El caso de la morgue judicial", Juan Pablo Bohoslavsky, (ed.). Ud. también, Doctor?" Complicidad de jueces, fiscales y abogados durante la dictadura. Buenos Aires, Siglo XXI, 2015, pp. 147-162.

${ }^{6}$ Esteban Pontoriero, "Pensamiento militar y legislación de defensa en la Argentina: la caracterización de la amenaza a la seguridad interna ¿continuidad o ruptura? (1963-1970)”, Contemporánea, vol.3, no.3, pp.149-162.
} 
Pablo Seguel, La organización de la represión y la inteligencia en la dictadura militar chilena. Del copamiento militar del territorio al surgimiento de la Dirección de Inteligencia Nacional: Región Metropolitana, 1973-1977, Izquierdas, 49, abril 2020:767-796

violaciones a los derechos humanos cometidos por las dictaduras militares, evidenciando el carácter instrumental de la represión en diversos contextos políticos y sociales ${ }^{7}$.

Para el caso chileno, el desarrollo historiográfico del pasado reciente en relación a la dictadura militar ha puesto mayor énfasis en la dimensión político civil, más que en el estudio específico de los dispositivos represivos y de los servicios de inteligencia ${ }^{8}$. Los trabajos de la historiadora Verónica Valdivia han contribuido a cuestionar el carácter excepcional del uso de los dispositivos represivos, tanto en los orígenes de la formación del pacto social que dio origen al Estado chileno en el periodo de compromiso de clases ${ }^{9}$, como en el desarrollo de la política estratégica de la Unidad Popular en relación a las fuerzas armadas y policiales ${ }^{10}$ y las diversas estrategias de vinculación e integración de las clases populares al proyecto de la dictadura militar ${ }^{11}$. Por otra parte, otras investigaciones han permitido dar cuenta de los elementos de larga data del discurso anticomunista que configuró el imaginario de las fuerzas armadas chilenas y de sectores de la clase política nacional ${ }^{12}$; así como los componentes civiles en el apoyo de la dictadura militar y la orientación político-estratégica de las fuerzas armadas en términos de seguridad nacional ${ }^{13}$.

En torno a la represión política, algunos trabajos han explorado los vínculos estructurales y de mediano plazo en el desarrollo de la conflictividad popular, así como de la represión estatal ${ }^{14}$. Por otra parte, otros trabajos se han abocado al estudio de los vínculos latinoamericanos de los militares chilenos con la doctrina de la guerra contrainsurgente francesa ${ }^{15}$, así como sus conexiones con la Escuela Superior de Guerra de Brasil ${ }^{16}$. En particular en torno al accionar represivo y de inteligencia de las fuerzas armadas y policiales, así como de aparatos represivos paraestatales y clandestinos (Comando Conjunto Antisubversivo y el Servicio de Seguridad de Colonia Dignidad) y servicios de inteligencia (Dirección de Inteligencia Nacional, DINA, y Central Nacional de Informaciones, CNI), estos han sido impulsados

\footnotetext{
${ }^{7}$ Hernán Merele, El proceso represivo en los años setenta constitucionales. De la depuración interna del peronismo al accionar de las organizaciones paraestatales. En: G. Águila, S. Garaño y P. Scatizza (coor.), Represión estatal y violencia paraestatal en la bistoria reciente Argentina, Buenos Aires, Universidad Nacional de la Plata, 2016, 99-123. Ana Belén Zapata y Laura Rodríguez, "Violencia paraestatal en Mendoza y Bahía Blanca (1973-1976). Un enfoque comparativo”, Clepsidra, vol.4, 2017, pp. 102-119.

8 Danny Monsálvez, "La historia reciente en Chile: un balance desde la nueva historia política", Historia 396, Vol. 6, no. 1, 2016, pp.111-139. Igor Goicovic, "Temas y debates en la historia de la violencia política en Chile", Contenciosa, Año II, no. 3, 2014, p.17.

9 Verónica Valdivia, “Todos juntos seremos la historia: Venceremos" Unidad Popular y fuerzas Armadas”, Julio Pinto (coor. y ed.), Cuando hicimos historia. La experiencia de la Unidad Popular, Santiago de Chile, Lom Ediciones, 2017, pp. 177-206. Verónica Valdivia, "Chile: ¿un país de «excepción»? La Ley de Control de Armas y la máquina represiva puesta en marcha, Julio Pinto (coor. y ed.), Cuando hicimos historia. La experiencia de la Unidad Popular, Santiago de Chile, Lom Ediciones, 2014, pp. 205-232.

10 Verónica Valdivia, Subversión, coerción y consenso. Creando el Chile del siglo XX (1918-1938), Santiago de Chile, Lom Ediciones, 2017.

11 Verónica Valdivia, “Estamos en Guerra Señores. El Régimen Militar de Pinochet y el Pueblo, 1973-1980”, Historia, 43, vol. I, pp. 163-201. Verónica Valdivia, El golpe después del golpe. Leigh vs. Pinochet. Chile, 1960-1980, Santiago de Chile, Lom Ediciones, 2003.

Valdivia, 2003, 2007, 2010.

${ }^{12}$ Marcelo Casals, La creación de la amenaza roja. El surgimiento del anticomunismo en Chile a la «campaña del terron» de 1964, Santiago de Chile, Lom Ediciones, 2016.

13 Javier Rebolledo, El despertar de los cuervos. Tejas Verdes, el origen del exterminio en Chile, Santiago de Chile, Planeta, 2016. Manuel Guerrero, "Cuando la población se hace parte de la producción social de la violencia: El caso de la colaboración mediante denuncias", Ximena Póo, La dictadura de los sumarios (1974-1985), Santiago de Chile, Editorial Universitaria, 2016, pp. 175-195. Rolando Álvarez, Desde las sombras: una historia de la clandestinidad comunista (1973-1980), Santiago de Chile, Lom Ediciones, 2003. 14 Gabriel Salazar, La violencia politica popular e las "Grandes Alamedas". La violencia en Chile 1947-1987 (una perspectiva bistórico popular), Santiago de Chile, Lom Ediciones, 2006. Pedro Milos, Historia y memoria. 2 de abril de 1957, Santiago de Chile, Lom Ediciones, 2007.

${ }_{15}$ Cristian Gutiérrez, La Contrasubversión como politica. La doctrina de guerra revolucionaria francesa y su impacto en la FF.AA. de Chile y Argentina, Santiago de Chile, Lom Ediciones, 2018.

16 Eva Fisher, Colaboraciones transnacionales de los Servicios de Inteligencia en el Cono Sur en los años 1970 y 1980. El papel de Brasil en el contexto de la Operación Cóndor, Santiago de Chile, Documento de Trabajo, Museo de la Memoria y los Derechos Humanos, 2015.
} 
Pablo Seguel, La organización de la represión y la inteligencia en la dictadura militar chilena. Del copamiento militar del territorio al surgimiento de la Dirección de Inteligencia Nacional: Región Metropolitana, 1973-1977, Izquierdas, 49, abril 2020:767-796

con fuerza por textos de carácter testimonial y por el periodismo de investigación en desmedro de la historiografía ${ }^{17}$.

Salvo algunos estudios de casos de centros clandestinos de detención y campos de prisioneros políticos ${ }^{18}$, se ha desarrollado un tipo de investigación más centrada en figuras emblemáticas de la represión más que en abordajes sistemáticos y reconstructivos de la misma ${ }^{19}$. Esto ha repercutido a nivel metodológico en estudios de caso donde prevalece el uso de archivos de prensa y testimonios, en desmedro de otras fuentes de información como archivos judiciales, archivos de la represión y de derechos humanos ${ }^{20}$. En ese escenario, una mención especial requiere el trabajo de Magdalena Garcés, centrado en el accionar represivo de la DINA sobre el Movimiento de izquierda Revolucionaria (MIR) ${ }^{21}$, que metodológicamente trabaja con sentencias judiciales. Otro gran aporte en este enfoque lo constituye el trabajo de Camilo Plaza sobre el Servicio de Investigaciones ${ }^{22}$. Finalmente, el trabajo de Pablo Policzer, de corte más teórico que historiográfico, constituye un avance interesante en la construcción de un enfoque de observación que permite cruzar política y represión desde el prisma de los dispositivos represivos $^{23}$. Salvo estos trabajos, no existe ningún trabajo sistemático que se aboque al estudio y análisis de la represión, que integre desde un enfoque de redes, la dimensión de observación intermedia de un dispositivo represivo con el desarrollo de la coyuntura política.

Tomando en consideración estos antecedentes, este artículo pretende escrutar la relación entre los dispositivos, organizaciones e instituciones represivas con el ejercicio y despliegue de la represión durante los primeros años de la dictadura militar en la Región Metropolitana, específicamente entre 1973 y 1977. Por este motivo nos interrogamos por la organización y racionalidad de la DINA con el objetivo de analizar su funcionamiento y caracterizar su estructura organizacional, identificando los elementos que puedan constituirse en una ruptura con el desarrollo de la represión y la inteligencia dentro de las fuerzas armadas y policiales. Sin desconocer la organización de la inteligencia y la seguridad durante la década de 1960 por parte de las fuerzas armadas y policiales ${ }^{24}$, este artículo toma como foco en específico los meses anteriores al golpe de Estado de 1973 en la región antes señalada por motivos de extensión.

A nivel teórico, los trabajos de Daniel Feierstein y la corriente de estudios sobre genocidios han instalado la problemática del terrorismo de Estado en el contexto regional y global a través de la categoría

\footnotetext{
17 Manuel Salazar, Las letras del horror. Tomo I: La Dina, Santiago de Chile, Lom Ediciones, 2014. Manuel Salazar, Las letras del horror. Tomo II: La CNI, Santiago de Chile, Lom Ediciones, 2014. Mónica González y Héctor Contreras, Los secretos del Comando Conjunto. Santiago de Chile, Editorial Ornitorrinco, 1991. Evelyn Hevia y Jan Stehle (ed.), Colonia Dignidad: diálogos sobre verdad, justicia y memoria, Santiago de Chile, El Desconcierto, 2015. Manuel Ahumada, Cerro Chena. Un campo de prisioneros, Santiago de Chile, autoedición, 2011. Javier Rebolledo, El despertar de los cuervos. Tejas Verdes, el origen del exterminio den Chile, Santiago, Planeta, 2016. Herman Schwember, Delirios e indignidad. El estéril mundo de Paul Schäfer, Santiago de Chile, J.C. Sáez Editor, 2009. Friedrich Paul Heller, Pantalones de cuero, moños... y metralletas. El trasfondo de Colonia Dignidad, Santiago de Chile: CESOC, 2007.

18 Gabriel Salazar, Villa Grimaldi (Cuartel Terranova). Vol. I. Historia, testimonio, reflexión. Santiago de Chile, Lom Ediciones, 2013. Sady Arenas, La sorda justicia. El "Hoyo" de José Domingo Cañas, Cuartel Ollägue de la DINA, Santiago de Chile, Fundación José Domingo Cañas, 2016. Pascale Bonnefoy, Terrorismo de Estadio. Prisioneros de guerra en un campo de deportes, Santiago de Chile, Editorial latinoamericana, 2016. Joaquín Real, Prisioneros de Guerra en Aysén, Santiago de Chile, Ediciones Kultrún, 2014.

19 Nancy Guzmán, Ingrid Olderock. La mujer de los perros, Santiago de Chile, Ceibo Ediciones, 2014. Manuel Salazar, Contreras. Historia de un intocable, Santiago de Chile, Uqbar editores, 2014. Nancy Guzmán, El Fanta: historia de una traición, Santiago de Chile, Ceibo Ediciones, 2016. Nancy Guzmán, Romo: Confesiones de un torturador, Santiago de Chile, Planeta, 2000. Luz Arce, El Infierno, Santiago de Chile, Tajamares Editores, 2017. Mónica Echeverría, Krassnoff arrastrado por su destino, Santiago de Chile, Catalonia, 2011. Daniel Campusano, Macarena Chinni, Constanza González y Felipe Robledo, Álvaro Corbalán: El dueño de la noche, Santiago de Chile, Ceibo Ediciones, 2015.

${ }^{20}$ Varios Autores, Archivo y memorias de la represión en América Latina (1973-1990), Santiago de Chile, Lom Ediciones, 2015.

21 Magdalena Garcés, Terrorismo de Estado en Chile: la campaña de exterminio de la DINA en contra del MIR. Tesis doctoral, Salamanca, Universidad de Salamanca, 2016.

22 Camilo Plaza, El Servicio de Investigaciones y la Policía Politica en Chile (1933-1973), manuscrito inédito, 2019.

23 Pablo Policzer, Modelos del horror. Represión e información en Chile bajo la Dictadura Militar, Santiago de Chile, Lom Ediciones, 2014. 24 Una de las observaciones efectuadas por la historiadora Verónica Valdivia a este trabajo dice relación con la importancia de profundizar en la organización de las fuerzas armadas durante la década de 1960. Por motivos de extensión, se hace imposible en este trabajo abordar este periodo.
} 
Pablo Seguel, La organización de la represión y la inteligencia en la dictadura militar chilena. Del copamiento militar del territorio al surgimiento de la Dirección de Inteligencia Nacional: Región Metropolitana, 1973-1977, Izquierdas, 49, abril 2020:767-796

"práctica social genocida"25. No obstante, los trabajos de la Red de Estudios Sobre Represión y Violencia Política han sostenido críticas a este concepto por tomar como referencia la elaboración dada por el derecho internacional a través del planteamiento de Raphael Lemkin y la Convención para la Prevención y Sanción del Delito de Genocidio de 1948. La principal crítica sostenida dice relación con la exclusión de los grupos políticos como víctimas de la violencia de Estado y la concepción estatal del ejercicio de la violencia política, que en algunos casos va en desmedro de las articulaciones paraestatales ${ }^{26}$. En segundo lugar, algunos estudios han cuestionado el alcance explicativo de la noción de experiencia concentracionaria acuñada por Pilar Calveiro ${ }^{27}$ por cuanto toma como referencia de las prácticas de violencia estatal y paraestatal a la experiencia propia del campo de concentración, lo que dificulta identificar las dimensiones específicas de los centros clandestinos de detención y tortura articulados con las burocracias de Estado.

Siguiendo a Jean Paul Brodeur ${ }^{28}$, las burocracias que legamente se abocan a las labores represivas corresponden a aquellas que tiene mandatos legales de administración del monopolio de la violencia física: las fuerzas armadas y policiales, las cuales están diferenciadas funcionalmente. Las burocracias militares, administran las labores de defensa en escenarios de guerra externa e interna; las policiales, se abocan a la administración y resguardo del orden público. Para el desarrollo de las funciones de las burocracias militares y policiales, se contemplan las labores de recopilación de información y de análisis de la misma: la inteligencia. Dada la complejización de las sociedades contemporáneas, así como de los escenarios de conflicto intra e interestatal, las funciones de inteligencia se formalizan y, en determinadas coyunturas, se constituyen en servicios diferenciados. Desde este punto de vista, emergen las burocracias de información e inteligencia.

Dado que el ejercicio de la represión y la inteligencia muchas veces está en el límite de la legalidad, una comprensión del desarrollo histórico de las mismas debe prescindir de un criterio formal de análisis para escrutar las maneras en cómo históricamente se producen las funciones militares, policiales y de inteligencia ${ }^{29}$. Desde este punto de vista, el enfoque de observación más que hacia las orientaciones normativas o los marcos legales que las sustentas debe abocarse a las maneras en cómo históricamente se organizan y se vinculan con los dispositivos jurídicos, los aparatos paraestatales y estatales. Es decir, escrutar los puntos de articulación en los que las organizaciones burocráticas militares, policiales y de inteligencia ejecutan la represión, el control y la inteligencia política en un contexto político particular.

Para los fines de esta investigación las burocracias como cuerpos normados y organizados del Estado son los agentes que efectúan y materializan la represión, el control y la inteligencia ${ }^{30}$. No obstante, dado que históricamente la represión de Estado es un tipo de violencia que combina repertorios legales e ilegales, se expresa en organizaciones normadas legalmente (burocracias) y en organizaciones que adoptan modos de organización clandestino e ilegal. En otras palabras, la represión, el control y la inteligencia de Estado combinan repertorios de hecho y de derecho. La dimensión transversal a ambas es la organizacional, por cuanto las acciones requieren de cadenas de mandos, marcos normativos y de autoridad que les permitan justificar su accionar. Por ello las organizaciones se expresan en redes de

${ }_{25} 5^{\prime} \mathrm{El}$ concepto de práctica social genocida fue creado para dar cuenta de los elementos comunes presentes en el uso del dispositivo concentracionario en distintos casos históricos, y busca abarcar el conjunto de los genocidios que se propusieron la reorganización de las relaciones sociales en aquellos territorios en aquellos territorios en los que se implementaron (...)”, Daniel Feierstein, Introducción a los estudios sobre genocidio, Buenos Aires, Fondo de Cultura Económica, 2016, p. 30.

$26 \mathrm{Al}$ interior del mismo campo de estudios sobre genocidio, Martin Shaw efectuó una acuciosa revisión del concepto desde la sociología que lo llevó a una reformulación del genocidio entendido como relación social, incluyendo por ende los grupos políticos, la violencia paraestatal y los componentes culturales en esta práctica social. Martin Shaw, ¿Qué es el genocidio?, Buenos Aires, Prometeo Editores, 2014.

27 Pilar Calveiro, Poder y Desaparición, Buenos Aires, Coligüe, 2014.

28 Jean-Paul Brodeur, Las caras de la policía, Buenos Aires: Prometeo, 2011. Dominique Monjardel, Lo que hace la policía: sociología de la fuerza pública, Buenos Aires, Prometeo, 2011

${ }^{29}$ Brodeur, op. cit.

30 Wolgang Sofsky, La organización del terror. Los campos de prisioneros, Buenos Aires, Prometeo, 2016. 
Pablo Seguel, La organización de la represión y la inteligencia en la dictadura militar chilena. Del copamiento militar del territorio al surgimiento de la Dirección de Inteligencia Nacional: Región Metropolitana, 1973-1977, Izquierdas, 49, abril 2020:767-796

interacciones, agentes, prácticas y discursos. Para efectos de esta investigación, el análisis de redes ${ }^{31}$ tiene rendimiento en términos de expresión de la materialidad de los circuitos interacción de una cadena organizacional, permitiendo dar cuenta de los grupos, cadenas de mando y roles de los agentes y civiles de diversa naturaleza. Metodológicamente, la reconstrucción de la organización se efectúa a partir de la interpretación sentencias judiciales instruidas por el poder judicial en causas de derechos humanos, el análisis de informes policiales de la Brigada Investigadora de Delitos contra los Derechos Humanos de la Policía de Investigaciones ${ }^{32}$, bibliografía especializada y la utilización de los archivos de inteligencia de Estados Unidos desclasificados, relacionados al accionar de la DINA en Chile y en el extranjero ${ }^{33}$.

La hipótesis de esta investigación en curso es que la DINA ${ }^{34}$, pese a constituirse formalmente en un servicio técnico militar de carácter profesional dependiente de la Junta Militar de Gobierno, en la práctica se constituyó en un dispositivo represivo, de control e inteligencia al servicio de la consolidación del poder personal del General Augusto Pinochet Ugarte. Para ello implementó una estructura organizacional altamente jerarquizada, compartimentada y diferenciada funcionalmente orientada hacia las labores de represión, pero también hacia la coordinación de las políticas de Estado impulsados por el régimen militar. Esto le permitió acelerar la neutralización de los enemigos políticos del régimen, el silenciamiento de eventuales cuestionamientos al curso de este por parte de sus aliados y adversarios y el disciplinamiento del conjunto de la sociedad a través del control del aparato público y una densa red de informantes civiles. Para ello implementó un repertorio de operaciones de inteligencia, control y represión, que combinó acciones legales e ilegales, efectuando un tratamiento diferenciado de las mismas: a los enemigos del régimen buscó eliminarlos a través del desarrollo de detenciones, torturas, ejecuciones y desapariciones (todas aquellas personas asociadas a las militancias de los partidos de izquierda que respaldaron la Unidad Popular y aquellos que se situaron en tensión con ella misma). A los adversarios del régimen y del poder personal de Augusto Pinochet (tanto al interior del Ejército y las otras ramas de las fuerzas armadas y orden, como al interior de la clase política civil), buscó neutralizarlos mediante el uso de dosis de violencia disuasiva. Finalmente, al conjunto de la sociedad buscó disciplinarla y controlarla mediante operaciones psicológicas, de propaganda negra y una compleja red delación y espionaje que recorrió el aparato público y las diversas organizaciones de la sociedad civil.

\section{Represión e inteligencia en el seno de las fuerzas armadas y policiales.}

Previo al golpe de Estado del 11 de septiembre de 1973 las funciones de represión y control quedaron escindidas de las labores propias de la inteligencia estratégica ${ }^{35}$. La represión y el control quedaron comprendidas como funciones propias del mantenimiento del orden público propio de la función policial al interior del Estado, mientras que las labores de información e inteligencia estratégicas fueron desarrolladas por las fuerzas armadas y la Dirección General de Investigaciones ${ }^{36}$. La inteligencia

\footnotetext{
${ }^{31}$ Michel Bertrand y Claire Lemercier, "Introducción: ¿en qué punto se encuentra el análisis de redes en Historia?”. Redes. Revisa hispana para el análisis de redes sociales, 2011, Vol. 21, 1, 1-12. Ulrick Brandes, Patrick Kenis y Jörg Raab, "La explicación a través de la visualización de redes". Redes. Revista hispana para el análisis de redes sociales, 2005, Vol. 9, 1, 1-11.

$32 \mathrm{El}$ valor histórico de este corpus documental fue reconocido por el Estado chileno a través de la protección de los mismos como Monumentos Históricos. Decreto del Ministerio de Educación N 79 del 28 de febrero de 2018.

33 US Departamento of State, Chile Declassification Project: https:// foia.state.gov/

34 Agradezco la información entregada y las conversaciones con Mauricio Weibel que me han permitido reorientar la investigación de lo meramente represivo, hacia las funciones de control y planificación política de los servicios de inteligencia.

35 "La información o inteligencia estratégica, como se le llama, es aquella rama de la inteligencia que busca el conocimiento de las capacidades, vulnerabilidades y probables cursos de acción o posibilidades de una nación cualquiera, en especial de aquellas con las que se tiene más relaciones o vínculos políticos, económicos, sociales y militares". Julio Canessa, "Introducción al Estudio de la Información Estratégica", Memorial del Ejército, año LVIII, Nº 324, p. 14.

${ }^{36}$ Las labores de investigación secretas en Chile tienen sus antecedentes en el siglo XIX con la creación de la Policía Secreta de Valparaíso y la Guardia Municipal de Santiago en 1864. Hacia finales del siglo fueron conformadas como cuerpo de Policías Fiscales. Durante el siglo XX, fue agrupada por Carlos Ibáñez del campo al interior de carabineros en 1927 y en 1932 escindidas
} 
Pablo Seguel, La organización de la represión y la inteligencia en la dictadura militar chilena. Del copamiento militar del territorio al surgimiento de la Dirección de Inteligencia Nacional: Región Metropolitana, 1973-1977, Izquierdas, 49, abril 2020:767-796

estratégica quedó comprendida en el seno de los diversos servicios de inteligencia de las fuerzas armadas ${ }^{37}$ y su orientación apuntó sobre todo al desarrollo de inteligencia exterior en relación con la defensa nacional en casos de conflicto exterior ${ }^{38}$. Salvo las secciones II de inteligencia (también conocidos como departamentos II de inteligencia), orientados a la verificación de las declaraciones de historial personal ${ }^{39}$ en las propias filas de las fuerzas armadas, la inteligencia por motivos de orden interno del Estado no era una cuestión abordada al parecer de manera sistemática por las fuerzas armadas.

La progresiva militarización de las funciones policiales ante los escenarios de conflictividad social en el periodo 1960-1970, en el contexto de desarrollo de la Guerra Fría, fue uno de los factores que contribuyó al desarrollo de la inteligencia política al interior de las fuerzas armadas. En la medida que éstas progresivamente comenzaron a desarrollar funciones de estabilización política, en el marco de la política de seguridad hemisférica impulsada por Estados Unidos en el continente y los Programas de Asistencia Militar (Military Assitence Programs). Esto propició que se desarrollara un tipo de inteligencia estratégica abocada a los escenarios de conflicto interno en casos de situaciones de inestabilidad política y de excepción constitucional. Algunos hitos marcarán un punto de inflexión al respecto: Por una parte, la aprobación de la Ley de Control de Armas en octubre de 197240, la generación por parte del Estado Mayor de la Defensa Nacional del Plan Lautaro dado a conocer el 17 de agosto de $1973^{41}$ y el desarrollo del proceso por parte del Servicio de Inteligencia Naval en contra de un grupo de marinos con vínculos con la izquierda chilena en las localidades de Valparaíso y Concepción durante ese mismo mes ${ }^{42}$.

Uno de los elementos poco estudiados por la historiografía chilena y parcialmente señalado por el periodismo de investigación ${ }^{43}$, dice relación con el desarrollo de los Comandos de Acción Jurisdiccional de la Situación Interna (CAJSI) elaborados por el Ministerio de Defensa Nacional en el marco del Plan Lautaro. Estos comandos de carácter operativo y estratégicos fueron desarrollados y concebidos para situaciones de excepción constitucional por parte de las fuerzas armadas y contemplaron una distribución política y geográfica del territorio nacional. El Departamento V de la Policía de Investigaciones los definió como "un organismo de coordinación de inteligencia creado para ejercer las funciones jurisdiccionales, asignadas a los comandantes y almirantes operativos a lo largo del país" 44. Como ser verá más adelante, esta facultad fue delegada por la Junta Militar a través de bandos militares y finalmente legalizada a través de la declaración del Estado de Emergencia.

Estos espacios de coordinación de las diversas fuerzas armadas tuvieron un rol preponderante en el desarrollo de la organización de la represión durante los primeros días del golpe de Estado y

por el presidente Arturo Alessandri Palma, creándose el Servicio de Investigaciones (con posterioridad Dirección General de Investigaciones). Una de las labores destacadas de este servicio en materia de inteligencia fue la creación del D-50 abocado a la desarticulación de las redes del nacismo en Chile durante la década de 1940-50. Plaza, op. cit.

${ }_{37}$ Servicio de Inteligencia Miliar (SIM) en el caso del Ejército, Servicio de Inteligencia Naval (SIN) en el caso de la Armada y el Servicio de Inteligencia de Fuerza Aérea (SIFA) de Chile.

38 Julio Canessa, "Introducción al Estudio de la Información Estratégica". Memorial del Ejército, año LVIII, N 324, 14-35. Julio Canessa, "Introducción al Estudio de la Información Estratégica (continuación)". Memorial del Ejército, año LVIII, N ${ }^{\circ}$ 325, 26-36. Julio Canessa, "Introducción al Estudio de la Información Estratégica (continuación)". Memorial del Ejército, año LVIII, N $326,43-52$.

39 Las Declaraciones de Historial Personal (DHP) corresponden al espontáneo otorgamiento de datos personales por parte de los efectivos de las Fuerzas Armadas. Tiene como objetivo efectuar análisis de inteligencia y prevenir eventuales infiltraciones de partidos políticos o servicios secretos de otros países en las filas propias. Dirección de Inteligencia Nacional, Curso C-1/0276. Básico de Inteligencia para SS.OO. Curso: Operaciones Secretas. Tema: Técnica de trabajo de informantes, manuscrito, 1976. En relación a la existencia de las secciones II de inteligencia: Declaración Judicial de German Stegmaier Alarcón, del 23 de noviembre de 2001. Causa Rol 03-02-F, Corte de Apelaciones de San Miguel, "San Bernardo", Fj. 118.

40 Valdivia, "Chile un país de excepción (...)", op. cit.

41 Garcés, op. cit., 173.

42 Jorge Magasich, Los que dijeron "No". Vol. I. Historia del movimiento de los marinos antigolpistas de 1973. Santiago de Chile, Lom Ediciones, 2008.

43 Mónica González, La Conjura. Los mil y un día del golpe, Santiago de Chile, Ediciones B, 2000. Bonnefoy op. cit.

${ }^{44}$ Informe Policial No 537 del 5 de noviembre de 2004, Causa Rol 126.461. Citado por: Garcés, op. cit., 174. 
Pablo Seguel, La organización de la represión y la inteligencia en la dictadura militar chilena. Del copamiento militar del territorio al surgimiento de la Dirección de Inteligencia Nacional: Región Metropolitana, 1973-1977, Izquierdas, 49, abril 2020:767-796

permitieron que la planificación del mismo y el copamiento militar de los principales núcleos urbanos se efectuase de manera coordinada. Al momento de materializarse el golpe de Estado, el copamiento militar del territorio siguió la distribución dada por el Plan Lautaro a través de los CAJSI. La represión desde ese punto de vista fue el resultado necesario del aseguramiento de la situación interna. Uno de los elementos claves para la identificación de los objetivos de la represión pasó por la definición del perfil de los enemigos a reprimir. Para ello el movimiento golpista identificó a los responsables de la crisis política, social y económica del país. A través del bando militar $\mathrm{N}^{\circ} 1$ el movimiento golpista señaló que su accionar se justifica ante " $\mathrm{El}$ constante incremento de los grupos armados paramilitares, organizados y entrenados por los partidos políticos de la Unidad Popular que llevarán al pueblo de Chile a una inevitable guerra civil" 45 . Mediante el Decreto Ley $\mathrm{N}^{\mathrm{o}}$ 1, el movimiento golpista constituida en Junta Militar de Gobierno amplió la concepción del enemigo a combatir, identificándolo como parte de un elemento externo de la sociedad chilena: "Chile se encuentra en un proceso de destrucción sistemática e integral de estos elementos constitutivos de su ser, por efecto de la intromisión de una ideología dogmática y excluyente, inspirada en los principios foráneos del marxismo-leninismo" 46

Esta justificación político-ideológica permitió que una vez materializado el golpe de Estado la represión se abocara en contra del amplio espectro de los partidos de izquierda, activistas sociales y dirigentes del aparato de Estado asociados al gobierno de la Unidad Popular. Para ello las labores de control territorial de la situación interna del país siguieron las distribuciones territoriales y jurisdiccionales trazadas por el Plan Lautaro. Estas fueron dadas a conocer inicialmente a través del Bando Militar $\mathrm{N}^{\circ}$ $16^{47}$, siendo finalmente explicitadas a través de la declaración del Estado de Emergencia, designando a los oficiales de las fuerzas armadas a carga de cada una de los provincias y departamentos ${ }^{48}$. Esto permitió darle una existencia legal a la distribución territorial dada por los CAJSI y demarcó territorialmente los ámbitos de acción de la represión. La única región que adoptó una estructura organizacional propia fue la Provincia de Magallanes donde se constituyó una Junta Militar Provincial, contando con la participación del Ejército, la Armada y la Fuerza Aérea, la cual estuvo vigente hasta el 20 de septiembre ${ }^{49}$. Con posterioridad adoptó la estructura delineada por el Decreto Ley $\mathrm{N}^{\circ} 4$. En esta región se conformó un órgano de inteligencia que condujo las labores represivas y que se constituyó por la confluencia de los diversos servicios de inteligencia de las fuerzas armadas: el Servicio de Inteligencia de la Región Militar Austral (SIRMA) ${ }^{50}$.

Esta estructura organizacional contempló entregar el comando de las funciones jurisdiccionales a la máxima autoridad militar en el territorio. En la mayoría del territorio los CAJSI contemplaron la entrega del mando al Ejército, salvo en las Provincias de Valparaíso y el departamento de Talcahuano y Tomé, entregadas a la Armada, y las provincias de Llanquihue y Chiloé, entregada a la Fuerza Aérea. Esta división territorial tendrá una importancia gravitante al momento de comandar la represión, el control y la inteligencia estratégica, lo que repercutirá en que en la práctica los diversos servicios de inteligencia -a excepción de lo ocurrido en Magallanes con el SIRMA- se disputaron la hegemonía las labores represivas.

En la Región Metropolitana se conformó el CAJSI Santiago, que quedó comandado por el general de Ejército Herman Brady. El general Brady se desempeñó como comandante de la II División del Ejército y de la Guarnición de Santiago, siendo designado Jefe de la Zona en Estado de Sitio. Ejerció, además, las funciones de Juez Militar de Santiago. En estas labores fue apoyado por estas labores por un Estado Mayor a cargo del coronel Orlando Ibáñez. Esta organización contempló cuatro departamentos

45 Bando Militar No 1, Santiago 11 de septiembre de 1973.

46 Decreto Ley Nº 1 del 11 de septiembre de 1973, publicado el 18 de septiembre de 1973.

${ }_{47}$ Bando $N^{\circ} 16$, en: Manuel Antonio Garretón, Roberto Garretón y Carmen Garretón, Por la fuerza sin la razón: análisis de los bandos de la dictadura militar, Santiago de Chile, Lom Ediciones, 1998.

48 Decreto Ley $\mathrm{N}^{\circ} 4$ del 11 de septiembre de 1973, publicado el 18 de septiembre de 1973.

${ }^{49}$ Comisión Nacional Sobre Prisión Política, Informe de la Comisión Nacional Sobre Prisión Política y Tortura, Santiago de Chile, 2005.

50 Mindy Cárcamo, Cristina Castillo y Yennifer Oliva, Palacio de las Sonrisas: Preservación de la Memoria Histórica de los Sucesos acaecidos en 1973 en Punta Arenas, Tesis, Punta Arenas, Universidad de Magallanes, 2013. 
de coordinación: el $1^{\circ}$ de personal, $2^{\circ}$ de inteligencia, el $3^{\circ}$ de operaciones y el $4^{\circ}$ de logística. El conjunto del territorio metropolitano fue dividido en cuatro zonas: CAJSI norte, a cargo del comandante del Regimiento Buin; CAJSI sur, a cargo comandante de la Base Aérea del Bosque, el CAJSI oriente a cargo del comandante de los Institutos Militares con asiento en la Escuela Militar y el CAJSI centro, a cargo del General Sergio Arellano Stark, con su cuartel en la Academia de Guerra del Ejército. Finalmente, contempló una agrupación de reserva a cargo del general del Ejército Sergio Palacios Ruhman. Dada la envergadura territorial e importancia del CAJSI centro en el CAJSI Santiago, se organizó un Estado Mayor para el mismo emulando los cuatro departamentos contemplados en la estructura metropolitana (Ilustración 1).

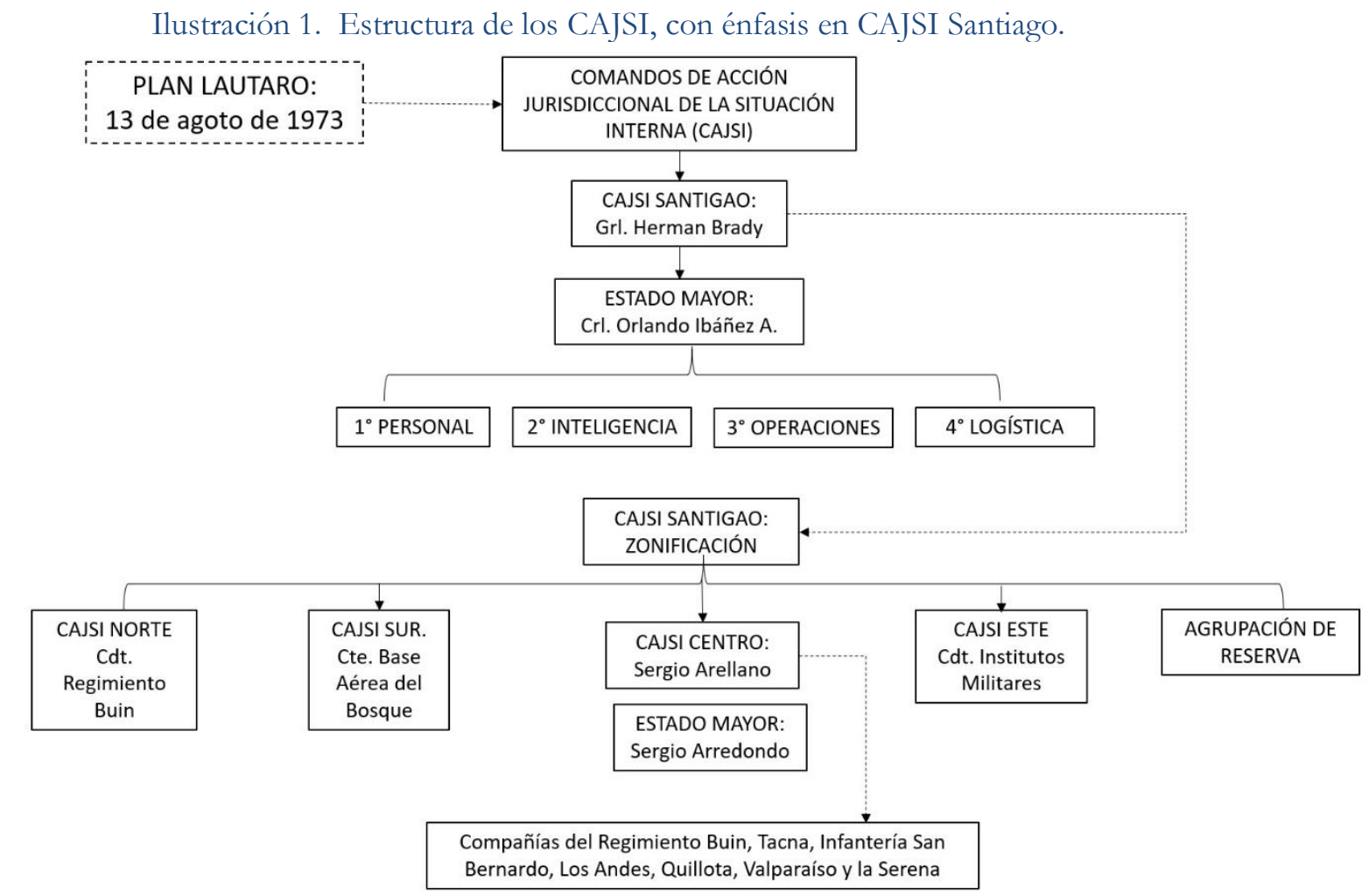

Elaboración propia en base a declaraciones de Oficiales de Alto Mando procedas por unidad policiales de la Policía de Investigaciones de Chile 51

Esta organización militar del territorio tuvo como resultado que en los primeros meses la represión fuese llevada adelante de manera masiva en contra de todos aquellos funcionarios públicos identificados con el régimen depuesto, dirigentes de los partidos políticos de la Unidad Popular, la izquierda en general y en contra de dirigentes sociales, sindicales y campesinos. Dadas las características del copamiento militar del territorio, los allanamientos y ocupaciones de predios, fábricas y diversos espacios sociales fueron coordinadas en conjunto por las fuerzas armadas, Carabineros y en menor

\footnotetext{
$51 \mathrm{Al}$ respecto: Informe Policial No 537 del 5 de noviembre de 2004, causa rol 126.461- MG, sustanciado por el ministro Miguel Vásquez Plaza, foja 5.050 e Informe Policial Brigada de Inteligencia Policial Metropolitana N 11 de 29 de abril de 2005. Causa rol 126.461, foja 6225. Informe Policial No 846 del 27 de mayo de 2008, causa rol 38.483 "Episodio Boinas Negras”, foja 4650. Informe Policial N 16 del 15 de diciembre de 2003, causa rol 2182-98, “Charles Horman”, foja 2685.
} 
Pablo Seguel, La organización de la represión y la inteligencia en la dictadura militar chilena. Del copamiento militar del territorio al surgimiento de la Dirección de Inteligencia Nacional: Región Metropolitana, 1973-1977, Izquierdas, 49, abril 2020:767-796

medida por investigaciones ${ }^{52}$. El mando de los operativos conjuntos dependió de la jurisdicción de cada CAJSI, siendo el más importante el CAJSI centro cuyos límites territoriales fueron Vicuña Mackenna al oriente, al poniente Estación Central, Quinta Normal y Cerrillos, al norte Recoleta e Independencia y al sur, hasta el Parque O'Higgins.

Para llevar adelante las labores represivas se utilizaron en Santiago las diversas guarniciones establecidas por la zonificación de los CAJSI y se habilitaron dos campos de prisioneros políticos: el Estadio Chile y el Estadio Nacional ${ }^{53}$. Junto con la masividad de las detenciones y las ejecuciones sumarias instruidas por consejos de guerra y por la aplicación de la ley de fuga, las lógicas represivas de las primeras semanas fueron de masividad y la publicidad de la misma. Correspondió en ese sentido a una represión no conducida por criterios de inteligencia estratégica, sino que, orientada políticamente a amedrentar a la población, desbaratar la base social de la Unidad Popular y a controlar el aparato Estatal.

Durante las primeras semanas las labores de inteligencia fueron desarrolladas por los oficiales adscritos a las secciones II de inteligencia de las fuerzas armadas y por comandos de fuerzas especiales, coordinados por los respectivos servicios de inteligencias de las fuerzas armadas y policiales. Para lidiar con la situación de los prisioneros de guerra y optimizar las labores de inteligencia el 16 de septiembre, la Junta de Gobierno instruye la creación de una comisión calificadora de detenidos, con la existencia de un departamento de inteligencia ${ }^{54}$. Pese a ello, las labores de inteligencia siguieron estando abocadas por los oficiales de inteligencia de las diversas ramas de las fuerzas armadas. Esto fue mucho más claro en el caso del Ejército -sobre todo en el caso de Escuela de Ingenieros de Tejas Verdes en Rocas de Santo Domingo en la Región de Valparaíso y en la Escuela de Infantería de San Bernardo en la Región Metropolitana ${ }^{55}$. En el caso de la Fuerza Aérea, esta se abocó a la investigación de las eventuales infiltraciones sobre su oficialidad para desbaratar las redes del Partido Socialista, del Partido Comunista y del Movimiento de Izquierda Revolucionaria. Esta diferenciación tendrá diversas consecuencias que serán fundamentales para comprender las tensiones originadas a lo largo de los años 1974, 1975 y 1976 entre la DINA y el Comando Conjunto, la agrupación paraestatal ideadas por el Servicio de Inteligencia de la Fuerza Aérea (Posterior Dirección de Inteligencia de la Fuerza Aérea), dependiente directamente de general del aire Gustavo Leigh para disputar en el plano de la inteligencia estratégica el poder del general Augusto Pinochet Ugarte ${ }^{56}$.

Durante las primeras semanas los equipos de interrogadores adscritos al Servicio de Inteligencia Militar y coordinados con las secciones II de inteligencia de las fuerzas armadas carecieron de eficiencia y en la práctica evidenciaron la inexistencia de un conocimiento previo en torno al desarrollo de las labores represivas. En la Región Metropolitana los operativos de detenciones eran conducidos por el Ejército y Fuerza Aérea con el apoyo de Carabineros; mientras que las labores de inteligencia eran

\footnotetext{
52 Sobre los allanamientos en las poblaciones del gran Santiago: Colectivo de Memoria Histórica José Domingo Cañas, Tortura en poblaciones del gran Santiago (1973-1990), Santiago de Chile, B\&J Impresores, 2005. Mario Garcés y Sebastián Leiva, El Golpe en la Legua, Santiago de Chile, Lom Ediciones, 2012. Sebastián Leiva, "La represión que no importó. La violencia estatal contra los delincuentes comunes tras el golpe de estado de 1973”, Ernesto Bohoslavsky, Marina Franco, Mariana Iglesias y Daniel Lvovich (comps.), Problemas de Historia Reciente del Cono Sur, Buenos Aires, Prometeo Libros/UNGS, 2011, pp. 99- 124.

53 Sobre el Estadio Nacional: Bonnefoy, op. cit. Fernando Guzmán, Estadio Nacional. La sangre o la esperanza, tesis, Santiago de Chile, Pontificia Universidad Católica de Chile, 2005. Sobre el Estadio Chile: Alexander San Francisco, Miguel Fuentes y Jairo Sepúlveda, "Hacia una arqueología del Estadio Víctor Jara: campo de detención y tortura masiva de la dictadura en Chile (19731974)", Revista de Arqueología Histórica Argentina y Latinoamericana, No. 4, 2010, pp. 91-116

54 Punto 4. Acta No 2, sesión Junta de Gobierno del 13 de septiembre de 1973.

55 El caso de la Sección II de inteligencia de la Escuela de Infantería de San Bernardo es interesante, por cuanto la historiografía hasta el momento no ha centrado su atención en su accionar represivo. De la investigación de fuentes judiciales y bibliográficas, se pueden acreditar cerca de 100 ejecutados por su accionar represivo y al menos 450 detenidos en el predio de entrenamiento del Cerro Chena. Causa Rol Nº3-02-F, San Bernardo. Ahumada, op. cit.

56 Sobre la hipótesis de la disputa política entre el Comando Conjunto Antisubversivo y la DINA: (González y Contreras, op. cit. Pablo Seguel, Aproximación a las prácticas represivas y organización del Comando Conjunto a través del análisis de sus centros clandestinos de detención, tortura y exterminio. Región Metropolitana, 1975-1977, inédito, 2019. Salazar, Villa Grimaldi, op. cit.
} 
Pablo Seguel, La organización de la represión y la inteligencia en la dictadura militar chilena. Del copamiento militar del territorio al surgimiento de la Dirección de Inteligencia Nacional: Región Metropolitana, 1973-1977, Izquierdas, 49, abril 2020:767-796

efectuadas por oficiales de inteligencia de ambas ramas con sus uniformes de combate y con un gran despliegue de fuerza:

Durante todo el mes de septiembre de 1973, la acción represiva del Gobierno Militar descansa, fundamentalmente, en la acción de tropas cuyo objetivo era asegurar el control de la situación (...) En el mes de noviembre, esta situación varía. Cada vez en mayor volumen, las detenciones las practican miembros de los Servicios de Inteligencia, siempre reforzados por personal uniformado y utilizando vehículos de las instituciones armadas ${ }^{57}$.

En el caso del Ejército, los interrogatorios fueron conducidos además por oficiales de fuerzas especiales. Si bien en la práctica contaron con el asesoramiento de oficiales de inteligencia brasileños como se ha comprobado para el caso del Estadio Nacional, no existió una concepción consolidada en torno a la inteligencia y la represión de carácter selectivo. En las provincias y departamentos regionales la represión tuvo diversas intensidades. Esto gatilló que hacia finales de septiembre de 1973 el general Sergio Arellano Stark condujera un operativo nacional conocido como Caravana de la Muerte, con el objetivo de "estandarizar y unificar criterios de administración de justicia" 58 . Como resultado fueron ejecutados cerca de un centenar de personas ${ }^{59}$. Durante ese mismo mes, en diversas localidades rurales se llevaron adelante una serie de operativos combinados entre civiles, carabineros y efectivos del Ejército que culminaron con la ejecución de cerca de doscientas personas ${ }^{60}$.

Entre septiembre y diciembre de 1973 fueron ejecutadas y /o desaparecidas 1.823 víctimas, de las cuales 1.275 fueron ejecutadas y 548 desaparecidas. Si se toma en consideración que en los 17 años de la dictadura militar fueron ejecutadas 3.197 víctimas calificadas por las comisiones de verdad y reconciliación ${ }^{61}$, el $60 \%$ de las víctimas ejecutadas se produce en este periodo (2.095) y el 49\% de las desapariciones forzadas (548 de 1.102 acreditadas a lo largo de la dictadura militar). Esto llevó a las comisiones de verdad y reconciliación a caracterizar este periodo de represión masiva, marcando su término con la creación de la DINA a mediados de 1974. No obstante, esta periodización dificulta evidenciar sus orígenes en el seno de las fuerzas armadas, sus variaciones y su lógica de funcionamiento, los cuales se enraízan en los primeros días del golpe de Estado y se vinculan con las acciones represivas desarrolladas por el grupo DINA en la Escuela de Ingenieros de Tejas Verdes en San Antonio. Al mismo tiempo, oculta le hecho que a lo largo del periodo en el que la DINA estuvo legalmente operativa, los diversos servicios inteligencias efectuaron operativos de inteligencia conjuntos y en algunos casos en abierta confrontación.

\footnotetext{
57 Comité de Cooperación para la Paz en Chile, Descripción de las acciones de los Servicios de Inteligencia del Gobierno Militar, febrero 1975, pp. 1-2.

58 Patricia Verdugo, Los zarpazos del puma. Caso Arellano, Santiago de Chile, CESOC / Ediciones Chile América, 1989.

${ }^{59} \mathrm{La}$ justicia solo acreditó la responsabilidad de la comitiva en el caso de 72 víctimas. No obstante, existen pruebas materiales que permiten atribuir la responsabilidad de la comitiva de Arellano de 4 víctimas ejecutadas en Curicó y de 12 de Valdivia, lo que da un total de 98 víctimas fatales.

${ }^{60}$ Los casos más emblemáticos corresponden a los ejecutados de Pisagua, Liquiñe, Chiuido, Laja -San Rosendo, Lonquén y Paine. Eugenio Ahumada, Rodrigo Atria, Jabier Luis Egaña, Augusto Góngora, Carmen Quersney, Gustavo Saball, Gustavo Villalobos, Chile la memoria probibida, Tomo I, II, III, Santiago de Chile, Pehuén, 1989.

${ }^{61}$ Por Comisiones de Verdad y Reconciliación (CVR) nos referimos al Informe de la Comisión Nacional de Verdad y Reconciliación (Informe Rettig), publicado y ampliado con posterioridad en el Informe de la Comisión Nacional sobre Reparación y Reconciliación, el Informe de la Comisión Nacional Sobre Prisión Politica y Tortura (Informe Valech) y el Informe del Consejo Asesor Presidencial para la calificación de Tortura. (Informe Valech II). Se excluye de esta denominación a las Mesas de Diálogo (1999-2001), por cuanto este espacio de carácter institucional no concluyó en la publicación de un Informe de Estado oficial, ni sugirió acciones en materia de verdad y reconciliación salvo la individualización de algunas víctimas que, algunas de las cuales con posterioridad fueron desmentidas.
} 
Pablo Seguel, La organización de la represión y la inteligencia en la dictadura militar chilena. Del copamiento militar del territorio al surgimiento de la Dirección de Inteligencia Nacional: Región Metropolitana, 1973-1977, Izquierdas, 49, abril 2020:767-796

\section{De la Comisión DINA a la creación legal de la Dirección de Inteligencia Nacional.}

En chile hay tres fuentes de poder: Pinochet, Dios y la DIN $A^{62}$.

La emergencia de la DINA marcó un punto de inflexión en el ejercicio de la represión y la inteligencia, por cuanto reemplazó desde el punto de vista operativo a los diversos servicios de inteligencia de las fuerzas armadas y policiales que actuaron con anterioridad al golpe de Estado. Se constituyó en torno a la Comisión DINA y de un grupo de oficiales del Ejército de la Escuela de Ingenieros de Tejas Verdes en la comuna de San Antonio, formados en las prácticas de la guerra contrainsurgente y en la Doctrina de Seguridad Nacional impulsado por Estados Unidos para América Latina ${ }^{63}$. La estructuración de un mando centralizado y jerarquizado dependiente directamente del presidente de la Junta Militar a la vez que su funcionamiento compartimentado, clandestino y al filo de la legalidad, implicaron que este servicio secreto de inteligencia política se proyectara como la mayor asociación ilícita existente a la fecha en la historia reciente de Chile, deteniendo, ejecutando, torturando y/o desapareciendo a cientos de militantes de izquierda y personas durante los cuatro años que estuvo formalmente operativa ${ }^{64}$.

Con anterioridad al golpe de Estado al interior del Ejército, un grupo de oficiales fue articulando una red de colaboración que decantó en una concepción determinada de las prácticas de guerra de contrainsurgencia (doctrina de guerra contrainsurgente francesa) y una noción determinada de la seguridad hemisférica (escuela norteamericana) que ha sido conceptualizada como Doctrina de Seguridad Nacional ${ }^{65}$. Dicha concepción no se articuló como un cuerpo doctrinario sistemático, sino más bien se configuró en torno a elementos de un discurso anticomunista ${ }^{66}$, a una concepción de la seguridad nacional vista desde el prisma del enemigo interno en el contexto de guerra fría y a una concepción de la guerra irregular en la que las operaciones de inteligencia, contrainteligencia, las operaciones sicológicas y la tortura son concebidos como medios legítimos para el resguardo de la seguridad interior del Estado ${ }^{67}$.

Este grupo se formó a partir de la reforma de la Academia de Guerra del Ejército (ACAGUE) en la década de $1950^{68}$ y participaron en los cursos de inteligencia de la Escuela de las Américas a través de los Programas de Asistencia Militar (Military Assistence Programs) coordinados por el Comando Sur de las fuerzas armadas de Estados Unidos. Según los datos del historiador Lesley Gill, por estas aulas pasaron cerca de 1.500 militares chilenos, formados en una determinada concepción de la inteligencia, la contrainteligencia y la represión contrainsurgente ${ }^{69}$. De la reforma de la ACAGUE en la década de 1950

\footnotetext{
${ }^{62}$ Frase dicha por un oficial del servicio chileno de información al agregado militar estadounidense, 6 de febrero de 1974. Citado por: Peter Kornbluh, Pinochet. Los archivos secretos, Barcelona, Crítica, 2013, p. 113.

63 Manuel Salazar, Las letras del horror: tomo I. La DINA, Santiago de Chile, Lom Ediciones, 2011. Mario Amorós, "La DINA el puño de Pinochet”, Ponencia presentada al 53 Congreso Internacional de Americanistas, México D.F, Julio de 2009,.

${ }^{64}$ Según la investigación de Magdalena Garcés, la DINA es la responsable de la ejecución y/o desaparición de 418 personas. Garcés, op. cit., p. 19

${ }^{65}$ Jorge Tapia, El Terrorismo de Estado: la Doctrina de Seguridad Nacional en el Cono Sur, México D.F., Nueva Imagen-Nueva Sociedad, 1980. Sobre el origen de la relación entre la doctrina de guerra contrainsurgente francesa y su relación con la doctrina de seguridad nacional: Daniel Feierstein, "la Doctrina de Seguridad Nacional en América Latina (1945-1989)", Introducción a los estudios de genocidio, Buenos Aires, Fondo de Cultura Económica, 2016, pp. 253-309.

Sobre la influencia de la doctrina francesa en la oficialidad del ejército chileno. Gutiérrez, op. cit.

${ }^{66}$ Casals, op. cit.

${ }^{67}$ Central Intelligence Agency, Kubark Counterintelligence Interrogation, manuscript, July 1963.

68 Alejandro San Francisco (ed.), La Academia de Guerra del Ejército de Chile, 1886-2006, Santiago de Chile, Centro de Bicentenario, 2006.

${ }^{69}$ No hay acuerdo respecto a las cifras. Manuel Salazar señala que fueron 1262. Salazar, Las letras... op. cit., p. 51. Magdalena Garcés también destaca esta influencia. Garcés, op. cit., 45-47. El historiador Lesley Gill señala que 1560 militares chilenos
} 
Pablo Seguel, La organización de la represión y la inteligencia en la dictadura militar chilena. Del copamiento militar del territorio al surgimiento de la Dirección de Inteligencia Nacional: Región Metropolitana, 1973-1977, Izquierdas, 49, abril 2020:767-796

y de la formación de la Escuela de Paracaidistas y Fuerzas Especiales de Ejército en 1965, provino el grueso de la oficialidad que conformó los diversos Servicios de Inteligencia, algunos de los cuales se desempeñaron como instructores de inteligencia en el ex Balneario Popular de Rocas de Santo Domingo usado por los oficiales de la Escuela de Ingenieros de Tejas Verdes para formar a los primeros agentes de la DINA70.

$\mathrm{Al}$ momento de efectuarse el golpe de Estado un grupo de oficiales conformó el "Comité de Coroneles" o "Grupo DINA", el cual el 17 de noviembre de 1973 pasó a formar la "Comisión DINA", dirigidos por el teniente coronel del Ejército Juan Manuel Guillermo Contreras Sepúlveda (Manuel Contreras) ${ }^{71}$. No obstante, los antecedentes del grupo DINA se remontan a los primeros días de septiembre de 1973, al puerto de San Antonio, específicamente la Escuela de Ingenieros de Tejas Verdes, dirigida por Manuel Contreras. Este fue uno de los impulsores de una concepción del terrorismo de Estado sin ambages, como una estrategia para combatir al enemigo interno formado por el comunismo, quien articuló y racionalizó una concepción personal de la inteligencia, las prácticas de muerte y el exterminio de la población civil ${ }^{72}$. Desde las primeras horas del golpe de Estado, Contreras pasó a tomar control de las acciones en el puerto de San Antonio, procediendo a detener a una decena de personas. Para ello dispuso de las dependencias de la Escuela de Ingenieros, formando el Campo de Prisioneros $\mathrm{N}^{0} 2^{73}$. Las primeras ejecuciones sumarias realizadas, acompañadas de un respectivo montaje comunicacional, se efectuó en contra de 6 dirigentes portuarios el 22 de septiembre. ${ }^{74}$

Los primeros interrogatorios fueron organizados por la sección II de inteligencia de la Escuela, en la Secretaría de Estudios de la institución y en el subterráneo del casino de oficiales ${ }^{75}$. Desde octubre de 1973 y tras la creación de la Comisión DINA, se asentó en la localidad el primer curso teórico y práctico sobre inteligencia, contrainteligencia e interrogatorios donde fueron destinados los primeros agentes $^{76}$. Este primer grupo, terminado su proceso de formación, se dirigió a las dependencias del cuartel $\mathrm{N}^{\circ}$ 1, en el subterráneo de la Plaza de la Constitución, dependiente del SICAR ${ }^{77}$. Al mismo tiempo se conformó la Brigada Femenina a cargo de la agente Ingrid Olderock, ex oficial de Carabineros, a quien se le encomendó el reclutamiento de un contingente de mujeres entre las postulantes rechazadas de las diversas fuerzas armadas y policiales ${ }^{78}$.

En estos primeros días la forma de operar adoptada se conformó en grupos de tareas denominadas Brigadas de Interrogatorios y Arresto (BIA). No hay certezas respecto al tiempo al que fueron denominadas de esta manera los grupos operativos. Al respecto el Comité de Cooperación para la Paz en Chile (COPACHI) señaló: "Al parecer la estructura de la DINA no es la misma hoy que la que pone en práctica inicialmente" (...) “Esta situación se pretender subsanar, al parecer, transformando esas

pasaron por sus aulas entre 1970 y 1976. Lesley Gill, Escuela de las Américas. Entrenamiento militar, violencia politica e impunidad en las Américas, Santiago de Chile, Lom Ediciones, p. 112.

70 Sentencia judicial causa rol No 2182-98 episodio “Tejas Verdes” instruida por el Ministro Alejandro Solis, 9 de agosto de 2010.

71 Mary Helen Spooner, Soldier in a Narrow Land: The Pinochet Regimen in Chile, Berkeley, University of California Press, 1999, p. 115. Citada por: Peter Kornbluh, Pinochet: Los Archivos Secretos, Madrid, Barcelona, 2013, p. 119.

72 "El Ejército Guerrillero es clandestino, no usa uniforme y se oculta dentro de la población civil (...) La iniciativa de la Guerra Subversiva la tiene el marxista clandestino, quien ataca cuando y donde quiere, oculto en la impunidad y buscando la sorpresa para causar el mayor daño (...) El guerrillero trata de simular que es un ciudadano normal, honesto y correcto y engaña hasta a su familia (...) En la Guerra Subversiva, como en Toda Guerra, habrá muertos, heridos y desaparecidos" (subrayado nuestro). Manuel Contreras, La verdad histórica. El Ejército Guerrillero I, Santiago de Chile, Editorial Encina Ltda, 2000, p. 16.

73 Rebolledo, op. cit., 52. Sentencia causa rol No 2182-98 episodio “Tejas Verdes".

74 "En San Antonio. 6 extremistas muertos al intentar fugarse", La Tercera de la hora, 24 de septiembre de 1973, p. 2.

75 Rebolledo, op. cit., p. 140.

76 Testimonio ex Agente DINA, José Nibaldo Jiménez Castañeda. Declaración judicial de abril de 2008, causa rol, 2182-98, “Insunza Bascuñán y Otros-Villa Grimaldi”, foja 1413. Este curso también es referido por la agente Ingrid Olderock. Guzmán, op. cit., pp. 220-222. Sentencia judicial causa rol No 2182-98 episodio “Tejas Verdes” instruida por el Ministro Alejandro Solis, 9 de agosto de 2010.

77 Sentencia Causa Rol 2182-98 “Operación Colombo-Jorge Grez” del 7 de mayo de 2014, p.120 y p. 156.

78 Guzmán, Ingrid Olderock, op. Cit. 
Pablo Seguel, La organización de la represión y la inteligencia en la dictadura militar chilena. Del copamiento militar del territorio al surgimiento de la Dirección de Inteligencia Nacional: Región Metropolitana, 1973-1977, Izquierdas, 49, abril 2020:767-796

varias brigadas en una sola, la Brigada de Interrogatorios y Arrestos"79. Lo agentes de inteligencia adoptaron un modo de funcionamiento clandestino, procediendo a generar los arrestos sin previo orden judicial y siendo los detenidos trasladados hacia el campo de prisioneros para con posterioridad ser interrogado bajo tortura por los equipos de inteligencia.

Este primer grupo constituyó la red principal de agentes de inteligencia a la que con posterioridad se sumaron los integrantes de la comitiva de la Caravana de la Muerte, constituyendo el núcleo central de la red DINA. La conformación de la DINA como un servicio de inteligencia política, que combinó un repertorio legal con el desarrollo de un amplio repertorio de acciones secretas y encubiertas, tuvo diversas consecuencias. La primera de ellas es que, a lo largo del periodo, organizacionalmente tuvo una cara legal, visible y un repertorio ilegal, clandestino y compartimentado. Lo segundo, su estructura organizacional nunca se mantuvo intacta, siendo constantemente reorganizada en función de los objetivos políticocoyunturales que se le fueron definiendo. Finalmente, implicó una permanente disputa con los diversos servicios de inteligencias de las fuerzas armadas.

Un punto de inflexión en ese sentido fue en el mes de noviembre cuando se constituye la Comunidad de Inteligencia de manera paralela a la Comisión DINA, con asiento en el inmueble de calle Juan Antonio Ríos $\mathrm{N}^{\circ}$ 6, en la comuna de Santiago. No existe certeza en torno a la fecha de inicio del accionar de la Comunidad de Inteligencia, así como su vínculo institucional con el Ministerio de Defensa Nacional y la Junta Militar de Gobierno. En el archivo desclasificado del Departamento de Inteligencia Americano, un mensaje del 28 de diciembre informa respecto a la creación de una nueva organización de inteligencia militar ${ }^{80}$ paralela a la Comisión DINA. Con posterioridad, con fecha 2 de febrero de 1974, el Departamento de Inteligencia Americana señala que dicha organización se constituyó en el Centro de Contrainteligencia de las Fuerzas Armadas (CECIFA). Esta organización dependiente del Ministerio de Defensa Nacional no sólo rivalizó con la comisión DINA en términos de los métodos y el tratamiento de los detenidos, sino que también en los alcances y en los estrechos vínculos de la DINA con el poder personal de Augusto Pinochet. Según esta fuente, el jefe de dicho servicio fue desempeñado por el capitán de corbeta Raúl Monsalve Poblete, quien fue “(...) un fuerte opositor de los métodos empleados por la DINA y un crítico de la subordinación de esta al General Pinochet" 81.

Hacia finales de 1973 el funcionamiento de la represión pasa progresivamente a estar conducida por las labores de inteligencia política, las cuales estuvieron en disputa entre la DINA y el CECIFA (Comunidad de Inteligencia). El COPACHI observó al respecto que “(...) ya hacia finales de 1973 la acción propiamente militar cede lugar notoriamente a la de los Servicios de Inteligencia" 82 . A pesar de aquello, no existió una coordinación activa entre la DINA y el CECIFA, generándose fuertes cuestionamientos a los métodos de tortura empleados por las Brigadas de Interrogatorios y Arresto de la DINA, siendo descritos por el agente informante del CECIFA como propios de la Inquisición española 83. Por los métodos de tortura empleados por la DINA y el fuerte crecimiento que experimentó desde comienzos de 1974, esta fue llamada el "Monstruo"84.

Hacia finales de 1973 se intentó revertir esta situación a través de la institucionalización de la DINA y la subordinación de las labores de inteligencia a su accionar. Un primer intento se encuentra en

\footnotetext{
${ }_{79}$ Comité de Cooperación para la Paz en Chile, Servicios de Inteligencia del Gobierno Militar, manuscrito, 1975, p. 7

80 "New Chilean Military Intelligence Organization", Department of Defense. National Military Command Center, 28 de diciembre de 1973.

81 "The Chief of CECIFA, LCDR Raúl Monsalve, has strongly opposed the methods employed by the DINA and critical of its subordination to General Pinochet vice [...] Ministry of Defense". Department of Defense Intelligence, "DINA \& CECIFA, Internal Conflicts and the Treatment of Detainees", 2 de febrero de 1974.

82 Comité de Cooperación para la Paz en Chile, "Los servicios de inteligencia del gobierno militar y los derechos humanos fundamentales. (Informe sobre la DINA y otros Servicios de Inteligencia)", manuscrito, 1975, 2.

83 "Source said that the their [DINA] technique are straight out of the Spanish Inquisition and often have the person interrogated with visible bodly damage", DINA \& CECIFA, Internal Conflicts and the Treatment of Detainees” op. cit.

${ }^{84}$ Idem.
} 
Pablo Seguel, La organización de la represión y la inteligencia en la dictadura militar chilena. Del copamiento militar del territorio al surgimiento de la Dirección de Inteligencia Nacional: Región Metropolitana, 1973-1977, Izquierdas, 49, abril 2020:767-796

el Decreto Supremo No 517 que creó la Secretaría Nacional de Detenidos (SENDET) en diciembre del año 1973. Tras el cierre del campo de prisioneros políticos del Estadio Nacional ${ }^{85}$ y la rehabilitación del campo de prisioneros del Estadio Chile, comenzó un proceso de reorganización de los prisioneros políticos, cerrándose los campos de prisioneros transitorios y habilitándose nuevas instalaciones. Entre noviembre de 1973 y junio de 1974 se cerraron los campos de prisioneros de lsla Dawson para los altos funcionarios del gobierno de la Unidad Popular ${ }^{86}$, el campo de prisioneros de Las Bandurrias en Aysén ${ }^{87}$, el campo de prisioneros $\mathrm{N}^{\circ} 2$ de la Escuela de Ingenieros de Tejas Verdes, el campo de prisioneros del cerro Chena dependiente de la Escuela de Infantería de San Bernardo. A la vez, se habilitaron en noviembre de 1973, el campo de prisioneros políticos de la ex oficina salitrera Chacabuco y en los ex Balnearios Populares de Ritoque y Puchuncaví 88 , la ciudad-puerto de Pisagua ${ }^{89}$ y el campo de prisionero de Tres Álamos en Santiago en junio de 197490.

En estos recintos estuvieron prisioneros aquellos detenidos procesados, condenados y/o a espera de ser sometido a un Consejo de Guerra por infracción del Estado de Sitio. Estos espacios constituyeron la cara visible de la represión: los prisioneros políticos. Para hacerse cargo de esta situación, la Junta de Gobierno creó la Secretaría Nacional de Detenidos al alero del Ministerio de Defensa Nacional, con el objetivo de "Coordinar con los diversos Ministerios las materias que digan relación con las personas que hayan sido privadas de su libertad en virtud de las facultades que confiere el Estado de Sitio" "1. Junto con ello, para legalizar el procedimiento de las detenciones que desde ese momento comenzarían a practicarse, la Junta Militar dictó el Decreto Ley N ${ }^{\circ} 228$ de enero de 1974 por el cual se declararon ajustadas a la ley los arrestos practicados desde el 11 de septiembre de 1973, señalando que, en lo sucesivo, sólo podrán arrestarse a las personas por Decreto Supremo del Ministerio del Interior dictado a nombre de la junta de Gobierno.

La Estructura de la SENDET quedó conformada por un departamento estadístico, uno administrativo, otro logístico y finalmente, el departamento de inteligencia -la fachada legal de la Comisión DINA y el primer intento por legalizar un modus operandis de la represión guiado por labores de inteligencia. El objetivo de dicho espacio fue:

(...) fijar las normas por las cuales se realizarán los interrogatorios o reinterrogatorios de los detenidos; determinar el grado de peligrosidad de éstos y mantener una coordinación permanente con los Servicios de Inteligencia de las Fuerzas Armadas, Carabineros e Investigaciones, con el fin de mantener al día las informaciones de que dispongan ${ }^{92}$.

La creación de la SENDET y la publicación del Decreto Ley N²28 buscaron institucionalizar la represión, legalizando de manera ex post los procedimientos efectuados y dotar de un aparente marco legal las detenciones y los interrogatorios a realizarse en lo sucesivo. Como señala el COPACHI:

\footnotetext{
85 "2.935 personas quedaron en libertad en Estadio Nacional”, La Tercera de la hora, 10 de octubre de 1973, p. 13. "Trasladaron a presos del Estadio Nacional", La Tercera de la hora, 8 de octubre de 1973.

86 Miguel Lawner, La vida a pesar de todo. Isla Dawson, Ritoque, Tres Álamos, Santiago de Chile. Sergio Bitar, Isla 10, Santiago de Chile, Pehuén, 1987.

87 Real, op. cit.

88 Lawner, op. cit.

${ }^{89}$ Lessie Jo Frazier, Salt in the sand. Memory, violence, and the nation-state in Chile, 1890 to the present, Durham y London, Duke University Press, 2007.

${ }_{90}$ Comité de Cooperación para la Paz en Chile, Informe sobre Comité de Cooperación para la Paz en Chile para la Paz en Chile, Informe sobre condiciones de vida en el Campamente Tres Alamos, manuscrito, 1975. Comité de Cooperación para la Paz en Chile, Situación de los detenidos de Pisagua, manuscrito, 1975. Comité por la Paz en Chile, Informe acerca de la Situación de los Detenidos en el Campamento Pisagua, manuscrito, 9 de febrero de 1975. Comité de Cooperación para la Paz en Chile, Visita del Comité para la Paz a la Oficina Chacabuco, manuscrito, s/a.

91 Artículo N 1, Decreto Supremo 517 del 31 de diciembre de 1973.

${ }_{92}$ Artículo N² 2, Decreto Supremo 517 del 31 de diciembre de 1973.
} 
Pablo Seguel, La organización de la represión y la inteligencia en la dictadura militar chilena. Del copamiento militar del territorio al surgimiento de la Dirección de Inteligencia Nacional: Región Metropolitana, 1973-1977, Izquierdas, 49, abril 2020:767-796

Este departamento de Inteligencia se crea para paliar los efectos de una todavía insuficiente coordinación de los servicios de inteligencia, y al margen de las funciones puramente normativas, asesoras y de coordinación, que la ley le entrega, se transformará, en las etapas siguientes en un nuevo y el más importante y desarrollado, servicio de inteligencia ${ }^{93}$.

En estos meses la represión y las detenciones ilegales no se detuvieron y tendieron a perfeccionarse, adoptando un modus operandis clandestino, selectivo y guiado por labores de inteligencia. La SENDET se asentó en las dependencias del ex Congreso Nacional en Santiago; la comisión DINA, bajo la fachada del departamento de inteligencia se asentó en el $2^{\circ}$ piso. Con posterioridad se trasladó al cuartel general al local confiscado a las Juventudes Comunistas, ${ }^{94}$ en calle Marcoleta No 90 , comuna de Santiago. No hay certeza del momento en el que finalmente la dirección de la DINA se asentó en calle Belgrado $\mathrm{N}^{\mathrm{O}} 11$ (actual calle Periodista José Carrasco Tapia); pero sí, que ambas dependencias quedaron conectadas por un pasillo interior ${ }^{95}$.

Durante estos primeros meses, los grupos operativos emularon la organización de las Brigadas de Interrogatorios y Arrestos, utilizando como cuarteles clandestinos el subterráneo del casino de oficiales de la Escuela de Ingenieros de Tejas Verdes, el cuartel $\mathrm{N}^{\circ} 1$ en el subsuelo de la actual Plaza de la Constitución, cerca del Palacio de la Moneda y el cuartel Yucatán (Londres 38), el primer centro clandestino masivo de detención y torturas.

A comienzos de enero de 1974 Augusto Pinochet Ugarte informó vía Oficio Secreto No 121 de la creación de la DINA a diversas autoridades militares. En este documento, identificó los objetivos de asesoramiento en materia de seguridad, solicitó la colaboración de las diversas fuerzas armadas y policiales y los exhortó a mantener el accionar de la DINA en secreto:

1.- Pongo en conocimiento de Usía que se ha creado la Dirección de Inteligencia Nacional (DINA) con personal de las Instituciones Armadas y Policiales de la República, organismo que asesorará a la Junta Militar en todas las materias referidas a la Seguridad Interior y Exterior del Estado, para lo cual dependerá exclusivamente de la Junta que horno presidir.

2.- Dadas las delicadas materias que el organismo asesor deberá tratar en las diferentes actividades del acontecer nacional, se solicita a Usía disponer que los medios de su dependencia presten la máxima colaboración de los miembros de la DINA cuando los sea requeridos, a la vez que guarden el más absoluto secreto de las investigaciones que les corresponda participar.

3.- Por obvias razones de elemental seguridad, las personas de los servicios de la dependencia de Usía, no podrán hacer comentarios o difundir lo obrado por los funcionarios de la DINA, e incluso les queda prohibido dar a conocer su existencia ${ }^{96}$.

Pese a que a través del Decreto $\mathrm{N}^{\mathrm{o}} 228$ se estipularon los alcances de las detenciones y los procesos de investigación, en la práctica la DINA se extendió hasta el punto de que: "puede establecer cortes en el curso legal de un caso, dejando sin recursos de acción a las Cortes Judiciales y otras agencias ejecutivas"97

En ese sentido, la creación de facto de la DINA antecede a su creación legal a través del decreto No521 de junio de 1974, por lo que su accionar represivo parte ya desde octubre de 1973. Entre ese periodo y la posterior creación legal de la DINA, las BIA se organizaron en pequeños grupos operativos,

${ }_{93}$ Corporación de Cooperación para la Paz en Chile, Descripción de las acciones de los servicios de inteligencia del gobierno militar, Feb. 1975, p. 3.

94 Francisco Poblete, "Con metralleta en la mano, la DINA expropió edificio de 500 mil dólares", La Época, domingo 14 de febrero de 1988.

95 'When DINA was firstsetting-up operatons, their headquarters were located in the house on Belgrado Street in Santiago (near the intersection of Vicuña Mackenna and Rancagua), Department of Defense, "Directorate of National Intelligence (DINA) Expands Operations and Facilities", 10 de abril de 1975, p.3

96 Oficio DINA (S) No 121, del 05.01.1974. "solicita apoyo nuevo organismo nacional"

${ }^{97}$ Department of Defense Intelligence, "DINA, Its Operations and Power”, 8 de febrero de 1974. 
Pablo Seguel, La organización de la represión y la inteligencia en la dictadura militar chilena. Del copamiento militar del territorio al surgimiento de la Dirección de Inteligencia Nacional: Región Metropolitana, 1973-1977, Izquierdas, 49, abril 2020:767-796

centrando su accionar en los focos de la resistencia del MIR y del PS. Durante este periodo, la persecución en contra del MIR se tornó crítica y en la Región Metropolitana fue disputada por la DINA y el SIFA. Con posterioridad al desarrollo del proceso de inteligencia efectuado al interior de las filas de la Fuerza Aérea, el SIFA logró infiltrarse en la red clandestina del Partido Comunista en la comuna de San Bernardo y en el aparato de seguridad de la Fuerza Central del MIR.

Esto aceleró la creación legal de la DINA dadas las tensiones entre estos servicios secretos, la que se materializó a través del Decreto Ley $\mathrm{N}^{\circ} 521$ de junio de 1974. A través de este documento legal, La DINA fue definida como:

(...) un organismo militar de carácter técnico profesional, dependiente directamente de la Junta de Gobierno y cuya misión será la de reunir toda la información a nivel nacional, proveniente de los diferentes campos de acción, con el propósito la inteligencia que se requiera para la formación de políticas, planificación y para la adopción de medidas que procuren el resguardo de la seguridad nacional y el desarrollo del país ${ }^{98}$.

En su artículo segundo creó el cargo de Director Nacional de Inteligencia y lo facultó para impartir instrucciones internas y resoluciones ante el resto de las instituciones para el funcionamiento de la institución. En relación a su organización interna, el artículo $\mathrm{N}^{\circ} 3$ estableció que "la organización, estructura institucional interna y deberes de la Dirección de Inteligencia Nacional serán establecidos por un Reglamento Orgánico Dictado (sic) a propuesta del director". En relación a su personal, se estableció en el mismo artículo que esta estaría formada por una planta de personal proveniente de las diversas instituciones de la Defensa Nacional y por personal civil, previa aprobación mediante decreto supremo del Ministerio de Hacienda.

En relación a las atribuciones del Director Nacional, el artículo 4 en la práctica le consagró un poder sin contrapesos:

(...) el Director de Inteligencia Nacional podrá requerir de cualquier servicio del Estado, municipalidades, personas jurídicas creadas por ley o de las empresas o sociedades en que el Estado o sus empresas tengan aportes de capital, representación o participación, los informes o antecedentes que estime necesario para el eficaz cumplimiento de sus cometidos.

Enfatizando, que las normas que establecen reserva o secreto a la información producida por el Estado en algunas reparticiones, no serían aplicables a la DINA.

Desde el punto de vista del financiamiento, el artículo $\mathrm{N}^{\circ} 6$ permitió una total ausencia de fiscalización en los gastos del servicio en la medida que sus montos solo fueron estipulados en sumas globales con cargo al Ministerio de Hacienda. En ese mismo plano, todas las importaciones y despachos efectuados por la DINA quedaron exentos de pago de aranceles. En síntesis, como señaló el COPACHI, este Decreto Ley en la práctica dejó a la DINA en inmejorables condiciones para desarrollarse. A través de esta "institucionalización" se le entregó un presupuesto global no sujeto a fiscalización, se le otorgaron franquicias aduaneras, se le permitió contratar el personal que estimase pertinente para el desarrollo de sus funciones, se le entregó infraestructura para su funcionamiento y se le otorgaron las atribuciones para hacerse con la información que estimase conveniente ${ }^{99}$.

Finalmente, un artículo único transitorio al final del decreto estipuló que los artículos $\mathrm{N}^{\circ}$ 9, 10 y 11 serían adjuntados al Diario Oficial en "un anexo de circulación restringida". Pese a que dichos artículos fueron de carácter reservado, la base de la CIA en Santiago logró acceder al contenido completo del Decreto 521 siendo adjuntado en un expediente remitido con antecedentes sobre la solicitud de extradición de Manuel Contreras a raíz del atentado y asesinato de Orlando Letelier y Ronnie Moffit en

\footnotetext{
98 Decreto Ley Nº 521 del 14 de junio de 1974, Crea la Dirección de Inteligencia Nacional.

${ }_{99}$ Comité de Cooperación para la Paz en Chile, Los servicios de inteligencia... op. cit.
} 
Pablo Seguel, La organización de la represión y la inteligencia en la dictadura militar chilena. Del copamiento militar del territorio al surgimiento de la Dirección de Inteligencia Nacional: Región Metropolitana, 1973-1977, Izquierdas, 49, abril 2020:767-796

Washington en 1976. En información desclasificada por el Congreso de Estados Unidos respecto a las acciones encubiertas de inteligencia en Chile, se adjuntó una copia del Decreto Ley 521 íntegro que creó la DINA:

Artículo $9^{\circ}$. El director de Inteligencia Nacional y los Jefes de los Servicios de Inteligencia dependientes de las Instituciones de la Defensa Nacional, podrán coordinar directamente sus actividades para el cumplimiento de misiones específicas. Sin perjuicio de lo anterior, y cuando lo reclame la necesidad imperiosa de la defensa del régimen institucional del Estado, la Junta de Gobierno podrá disponer la participación o coordinación de todos los organismos de Inteligencia anteriormente mencionados en funciones propias de la Dirección de Inteligencia Nacional.

Artículo $10^{\circ}$.Para el ejercicio de las facultades de traslado y arresto de personas, que se conceden por la declaración del Estado de Sitio u otras que puedan otorgarse por las circunstancias de excepción previstas en la Constitución Política, la Junta de Gobierno podrá disponer que las diligencias de allanamiento y aprehensión, si fueren necesario, sean cumplidas además por la Dirección de Inteligencia Nacional.

Artículo $11^{\circ}$. La Dirección de Inteligencia Nacional será la continuadora legal de la comisión denominada "DINA", organizada en el mes de noviembre de 1973100

Estos artículos secretos son fundamentales para dimensionar el proceso de institucionalización de la represión, así como la cadena de mando de la estructura organizacional de la DINA. Lo primero que evidencia este marco legal es que la DINA comenzó a operar de manera clandestina desde noviembre de 1973. Lo segundo es que el artículo $9^{\circ}$ reconoció en la práctica la disputa de los diversos servicios de inteligencia de las fuerzas armadas, los cuales quedaron subordinados a la DINA y esta la Junta Militar de Gobierno, la cual pasó a estar presidida desde junio por Augusto Pinochet ${ }^{101}$. Al respecto la CIA señaló que la DINA se constituyó en “(...) una organización de espionaje apta para todo tipo de servicios, semejante a una gendarmería militar"102

\section{La organización de la represión: orientaciones, estructura y funcionamiento de la DINA.}

Señores, la DINA soy yo $0^{103}$

En la práctica nunca se conoció el reglamento orgánico de la DINA estipulado en el artículo $\mathrm{N}^{\mathrm{o}} 3$ del Decreto Ley 521 de 1974, el que estableció su organización interna, estructura institucional y deberes. Motivo por el cual un desafío investigativo importante ha sido el poder establecer la estructura de la organización interna de la DINA, tomando en consideración la doble faz de su acción en la legalidad y en la clandestinidad. Para ello metodológicamente he cruzado la información proveniente de diversos informes periciales de la Policía de Investigaciones, declaraciones judiciales y extrajudiciales de ex agentes procesados por delitos en contra de los derechos humanos, sentencias judiciales, los archivos del COPACHI y de la Vicaría de la Solidaridad, la bibliografía existente sobre este tema y los archivos de inteligencia norteamericana desclasificados.

100 Decreto 521 de 1974, pp. 6 y 7. Supporting Documents submited with Manuel Contreras Brief Following Close of Sumario. Letelier/ Moffits Assassination, pp. 6-7.

101 Decreto Ley del Ministerio del Interior No 527 del 17 de junio de 1974.

102 Kornbluh, op. cit p. 119.

103 Frase dicha por Augusto Pinochet Ugarte en una reunión del comité de Generales en septiembre de 1974, ante los cuestionamientos señalados al accionar de la DINA por los generales Augusto Lutz y Óscar Bonilla. Fue grabada por el general Lutz quien se desempeñó como director del Servicio de Inteligencia Militar del Ejército hasta ese año. Ambos morirán en extrañas circunstancias en 1974 y 1975, respectivamente. Ernesto Ekaizer, "Pinochet dice: La DINA soy yo", El País, 17 de enero de 1999. 
Pablo Seguel, La organización de la represión y la inteligencia en la dictadura militar chilena. Del copamiento militar del territorio al surgimiento de la Dirección de Inteligencia Nacional: Región Metropolitana, 1973-1977, Izquierdas, 49, abril 2020:767-796

\section{Antecedentes para una caracterización de la DINA como un servicio secreto de inteligencia política}

Tomando como referencias el manual Operaciones Secretas de la Escuela Nacional de Inteligencia de la DINA del año 1976, creado para formar a sus propios agentes en materias de inteligencia, podemos aproximarnos a una caracterización de este servicio secreto de inteligencia política. La DINA puede definirse como un servicio secreto, entendiendo por ello a aquel servicio que realiza

(...) todo tipo de operaciones de inteligencia, en el país y en el extranjero mediante maniobras ocultas y clandestinas que no produzcan comprometimiento al Estado o a sus autoridades y que permita aprovechar sus resultados en beneficio de los intereses nacionales y de la propia organización ${ }^{104}$.

Para ello contempló el desarrollo de operaciones secretas, entendidas como "la suma de acciones o misiones clandestinas materializadas por técnicas secretas y realizadas con medios especializados del Servicio Secreto (sic)"105. Los principios del servicio secreto se estructuran en torno al manejo compartimentado de la información, a la vez que la centralización y coordinación del mando, el cálculo del riesgo político de las operaciones y el desarrollo sus operaciones de inteligencia y contrainteligencia combinando la clandestinidad con la legalidad:

El S.S. debe aprovechar que la gente piensa que la ley no será vulnerada. Esta credibilidad nos da la ventaja de vulnerar la ley. Lo interesante es que al actuar clandestinamente hay que saber hacerlo a objeto de mantener esta credibilidad. Ahora bien, la ley también ofrece una serie de garantías, las cuales deben ser explotadas con habilidades y en nuestro provecho ${ }^{106}$.

La estructura de los Servicios Secretos se caracteriza por desplegar su accionar en torno a redes de agentes y de informante. La organización en redes es una consecuencia estructural de la función organizacional y de los perfiles de los agentes que conforman la red: "La organización operativa es una consecuencia estructural. Se estructura la organización en REDES [sic], distribuyendo y ubicando a personal de acuerdo a sus capacidad especializada e idoneidad (...) equilibrando la eficacia con la seguridad"107. En torno este principio, se conforman las unidades permanentes, que contempla a las "redes que son estables en su estructura de A.S. [Agentes Secretos], que realizan sus tareas en zonas jurisdiccionales preestablecidas o trabajos muy especializados" 108 Los componentes de las unidades permanentes son: (a) la red de enlace, (b) la de reconocimiento y control, (c) las redes interiores, (d) exteriores y (e) las especiales.

Las redes de enlace están constituidas por agentes que “(...) dependen directamente de la Dirección de la organización y que realizan contactos y entendimientos oficiales semioficiales y clandestinos"109 con diversos organismos, autoridades e instituciones. Se caracterizan porque tiene agentes externos al mismo servicio. Las de reconocimiento y control, son agentes que dependen directamente de la dirección y "realizan reconocimientos preliminares a objetivos preliminarmente delicados o ejercen el CONTROL [sic] de la organización sobre las redes operativas (Brigadas o Unidades

104 Dirección de Inteligencia Nacional, Curso C-1/02-76, Básico de Inteligencia para SS.OO. Ramo: Operaciones secretas. Tema: Generalidades, características y objetivos del Servicio Secreto y los Agentes Secretos, 1976.

105 Dirección de Inteligencia Nacional, op. cit.

106 Idem.

107 Dirección de Inteligencia Nacional, Curso C-1/02-76. Básico de Inteligencia para SS.OO. Curso: Operaciones Secretas. Tema: Organización operativa (redes de informantes y redes de agentes), 1976.

108 Idem

${ }^{109}$ Idem. 
Pablo Seguel, La organización de la represión y la inteligencia en la dictadura militar chilena. Del copamiento militar del territorio al surgimiento de la Dirección de Inteligencia Nacional: Región Metropolitana, 1973-1977, Izquierdas, 49, abril 2020:767-796

Operativas)"110. Las redes interiores, son redes más abiertas ya que abarcan áreas territoriales extensas y contemplan agentes secretos e informantes. Las redes exteriores, están abocadas al accionar exterior al país. Finalmente, las redes especiales son redes ad hoc a los objetivos.

Como se señaló, la organización como una consecuencia estructural de la organización clandestina se configura en torno a los principios de la compartimentación y a jerarquización. La DINA definió la compartimentación como “(...) la organización y dirección de una organización clandestina, de tal forma que los miembros de un grupo conozcan solamente lo imprescindible respecto al personal, organización o actividad de otro grupo"111. Enfatizando, que la compartimentación “(...) puede existir también entre operaciones, entre ramificaciones de una operación o entre fases de una misma operación. También puede existir entre los escalones superiores e inferiores de la misma organización"112.

Por su parte, el principio de jerarquización apunta hacia la definición de la cadena de mando: "La cadena de mando, desde el escalón más elevado al más bajo, deberá estar claramente definida y conocida por todos los interesados. Una organización viene establecida deberá evitar contactos innecesarios entre elementos del mismo nivel"113.

Finalmente, en torno al modo de recopilar, sistematizar y organizar la información los servicios secretos conforman dos tipos de enlaces: las redes de control directo y las redes de control indirecto. Las primeras, se caracterizan porque "el informante es directamente responsable del agente de control" 114. Las segundas, "el informante clave o principal es una persona que trabaja bajo el control y la vigilancia directa del agente de control y que a su vez controla directamente uno o más de los informantes reclutados"115.

\section{La estructura y organización de la DINA}

La estructura y organización de la DINA se fue modificando en relación con las transformaciones de sus objetivos estratégicos, en relación con los enemigos del régimen, sus adversarios y la necesidad de controlar las acciones del conjunto de la sociedad. Este modelo de servicio secreto de inteligencia política marcó una ruptura radical con el modelo de organización de la represión y la inteligencia estipulado por las fuerzas armadas a través de los CAJSI en base a una distribución jurisdiccional del territorio geográfico. En los CAJSI las labores de inteligencia, de represión y de control se efectuaban de manera acotada por las tropas de las secciones II de inteligencia del comando a cargo de cada una de las zonas geográficas.

La DINA implementó un modelo que combinó una distribución geográfica jurisdiccional para las labores represivas, con distribuciones sectoriales para labores de control e inteligencia. De ese modo, los grupos operativos de carácter represivo, operaron de manera compartimentada según objetivos predefinidos por la Dirección Nacional al interior de una determinada jurisdicción territorial. Los grupos y brigadas abocadas a las labores de control e inteligencia, operaron de manera escindida al interior de un mismo sector, articulando densas redes de delación y espionaje (por ejemplo, en el caso de la Brigada de Inteligencia Económica o la Brigada de Inteligencia Ciudadana).

Evidenciando estas dificultades de coordinación de las secciones II de inteligencia de las fuerzas armadas, hacia noviembre de 1973 la Junta Militar instruyó la creación de la Comunidad de Inteligencia o CECIFA, en un intento de centralizar y coordinar las labores de inteligencia estratégica y de

\footnotetext{
110 Idem.

111 Dirección Inteligencia Nacional, C-1/02-76 Básico de Inteligencia para oficiales. Ramo: Operaciones Secretas. Tema: Medios para evadir la oposición activa, 1976.

112 Idem.

113 Idem.

114 Idem.

115 Idem.
} 
contrainteligencia. No obstante, la DINA emergió como un servicio secreto de inteligencia, como una policía política al servicio de Augusto Pinochet Ugarte ${ }^{116}$.

\section{Ilustración 2. La estructura de la DINA entre enero y junio de 1974.}

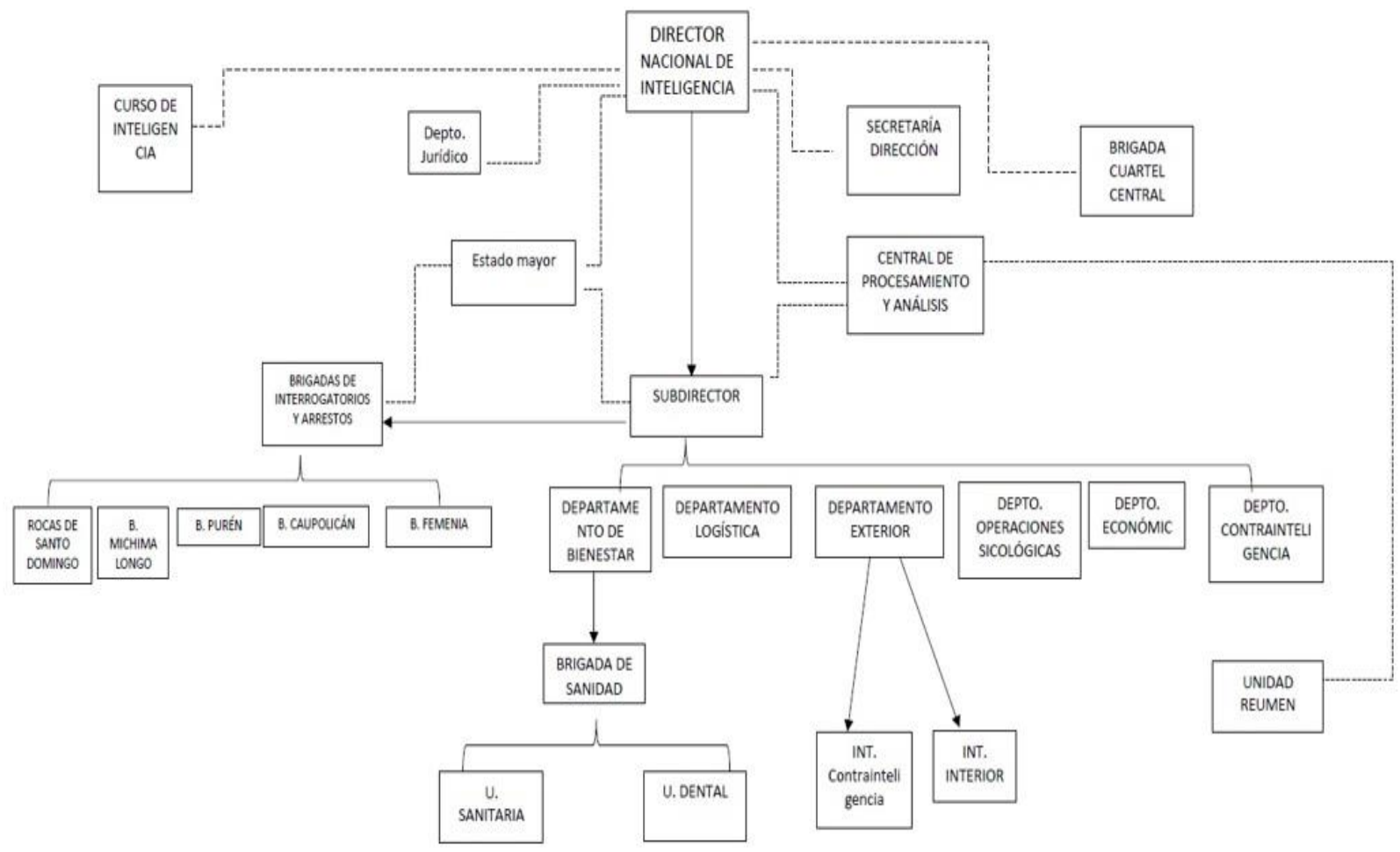

Elaboración propia en base a interpretación de declaraciones judiciales, informes policiales y bibliografia especializada.

En términos de sus objetivos trazados hacia los enemigos del régimen, la DINA inicialmente se abocó al combate del Movimiento de Izquierda Revolucionaria (MIR) entre 1973 y 1975. Paralelamente comenzó su seguimiento al Partido Socialista (1974-75) y, finalmente, se abocó con mayor ahínco en contra del Partido Comunista (1975-1976)117. Como afirma Magdalena Garcés "con la experiencia adquirida en su combate al MIR, la DINA fue "profesionalizándose", por lo cual sus acciones represivas se tornaron más selectivas y dejaron menos huellas, generando un mayor grado de compartimentación"118.

Esto implicó que las principales transformaciones de su estructura organizacional se observaron a nivel de sus grupos operativos, identificándose al menos cuatro grandes momentos: el de la formación

116 En información desclasificada, el agente Gerard Brechta señaló que la DINA era: “(...) una fuerza policial semejaste a la GESTAPO [...] otorga amplios poderes al director, Manuel Contreras [...] no parece haber restricción alguna a las operaciones de inteligencia que pueda emprender el director. En resumen, el decreto ley supone la aprobación legal y oficial de una organización que se encuentra ya en plena actividad, y potencialmente representa un golpe para las otras organizaciones de espionaje". Servicio de Inteligencia de Estados Unidos, Official Decree on the Creation of the National Intelligence Directorate (DINA), 2 de julio de 1974. Citado por: Salazar, Villa Grimaldi, op. cit, p. 65

117 Carmen Hertz, Apolonia Ramírez y Manuel Salazar, Operación exterminio. La represión contra los comunistas chilenos (1973-1976), Santiago de Chile, Lom Ediciones, 2016. Álvarez, op. cit.

118 Garcés, op. cit., 225. 
Pablo Seguel, La organización de la represión y la inteligencia en la dictadura militar chilena. Del copamiento militar del territorio al surgimiento de la Dirección de Inteligencia Nacional: Región Metropolitana, 1973-1977, Izquierdas, 49, abril 2020:767-796

de las Brigadas de Interrogación y Arresto al alero de la Comisión DINA, del cual se tiene muy poca información documental y judicial. El grupo que con posterioridad conformará la DINA se constituyó en torno a la Escuela de Ingenieros de Tejas Verdades, el desarrollo del campo de Prisioneros No. 2 anexo y al Balneario Popular Rocas de Santo Domingo. En Santiago, por su parte, utilizaron dos cuartes secretos para efectuar detenciones: cuartel Yucatán (Londres 38) ${ }^{119}$ y el Cuartel $\mathrm{N}^{\circ} 1$, en el subsuelo de la plaza de la Constitución cerca del palacio de la Moneda ${ }^{120}$.Por su parte, la Brigada Femenina fue trasladada al recinto confiscado al Movimiento de Acción Popular Unitaria en Calle Santa Lucía en el que con posterioridad funcionará la Brigada de Sanidad en la Clínica Santa Lucía ${ }^{121}$.

El segundo momento que va desde su institucionalización en la SENDET hasta su legalización a través del Decreto 517, momento en el cual la estructura organizacional diferenció las labores represivas- llevadas adelante por equipos operativos bajo la figuras de agrupaciones compartimentadas a cargo de un "analista de inteligencia" que conformaba parte de un Estado Mayor y las labores de Inteligencia, encomendadas a una Central de Procesamiento de información que compartía la información con el Estado Mayor, pero estaba directamente subordinada al Director Nacional (ver ilustración 2). En este momento el director se traslada al segundo piso del Ex Congreso y con posterioridad al local confiscado a las Juventudes Comunistas (Marcoleta $\mathrm{N}^{\circ}$ 90), el que con posterioridad será ampliado y trasladado a Belgrado 11. Los recintos clandestinos de este periodo fueron los mismos del periodo anterior, al que se agregó el ex fundo de la Universidad de Chile en Rinconada.

En el tercer momento se observa la reorganización más importante de la DINA con la desarticulación del Estado Mayor y la conformación de sus principales departamentos en dirección y subdirecciones, siendo las más relevante, la Dirección de Operaciones. Temporalmente va desde la legalización de la DINA con la publicación del Decreto 521 del 14 de junio de 1974 hasta la reorganización de la Brigada de Inteligencia Metropolitana hacia finales de 1975 y comienzos de 1976, marcado por la creación de la Brigada Lautaro. El Departamento de Defensa de Estados Unidos adjuntó en 1975 un diagrama con la estructura organizacional de la DINA ${ }^{122}$, el cual ha sido reproducido sin cuestionamientos por algunas investigaciones ${ }^{123}$.

Organizacionalmente, en la cúspide de la estructura estaba la 'Dirección nacional', apoyado por el 'departamento jurídico', el 'ayudante de director' y el equipo de seguridad, la 'Brigada Lautaro. Bajo ellos se situaba el Subdirector y operaban las Subdirecciones de Inteligencia Interior, la Subdirección de Inteligencia Exterior, Subdirección de Sanidad, Operaciones Sicológicas, Telecomunicaciones, Intendencia, Departamento de Personal y la Dirección de Operaciones. De la subdirección de inteligencia interior dependían las Brigadas de Inteligencia Económica y la Brigada de Inteligencia Electrónica. Desde el punto de vista de los recintos clandestinos, este momento está caracterizado por la emergencia del

\footnotetext{
119 La existencia de Londres 38 fue negada durante la década de 1970. En 1978 se constituyó en su lugar el juez Servando Jordán quien efectuó un informe descriptivo del estado de las instalaciones. Fue utilizado entre 1973 y 1975, concentrando su actividad represiva entre junio y agosto de 1974.

Melissa Figueroa, Memoria abierta y para el presente. Una caracterización de la construcción de memorias en Londres 38, Santiago de Chile, 2014. América Escobar, Memoria y Materialidad. Londres 38 un estudio de caso. Tesis para optar al título profesional de antropólogo. Concepción, Universidad de Concepción, 2011. Jorge Flores Durán, Londres 38 (un número desaparecido), Santiago de Chile, Editorial AUCO, 2003.

120 Si bien este cuartel dependió del Servicio de Carabineros (SICAR), fueron destinados a sus instalaciones los primeros agentes formados en el curso de inteligencia de Tejas Verdes durante el año 1973 y comienzos de 1974. Sobre su existencia: Véase sentencia causa Rol N 2182-98 episodio "Villa Grimaldi”, Cuaderno "Iván Insunza Bascuñán y otros”, del 21 de julio de 2017. Sobre los usos del recinto: Policía de Investigaciones. Laboratorio de Criminalística. Informe Pericial Fotográfico. N 49/2017, Causa Rol N 629-2010. Policía de Investigaciones. Laboratorio de Criminalística. Informe Pericial Planimétrico. N 109/2017, Causa Rol N 629-2010.

121 Romina Ampuero, Recinto DINA clínica Santa Lucia. Dossier de Investigación, manuscrito, 2018. Guzmán, op. cit. Sobre la confiscación del local: "Bodega con propaganda marxista hallan al MAPU”, La Tercera de la Hora, septiembre de 1973.

122 Department of Defense, "Organizational Diagram of The Directorate of National Intelligence (DINA), 16 de junio de 1975.

123 Ian Bradley Bob Lyles, The rise and fall of the DINA, 1973-1977, University of Texas at Austin, 2001, p.48.
} 
Pablo Seguel, La organización de la represión y la inteligencia en la dictadura militar chilena. Del copamiento militar del territorio al surgimiento de la Dirección de Inteligencia Nacional: Región Metropolitana, 1973-1977, Izquierdas, 49, abril 2020:767-796

cuartel Ollagüe124(José Domingo Cañas 1367), el cierre progresivo del cuartel Yucatán (Londres 38), la apertura del cuartel Tacora (conocido también como Venda Sexy, en calle Irán 3037) y la apertura del cuartel Terranova - el cuartel central de la Brigada de Inteligencia Metropolitana, hacia finales de 1974 (Villa Grimaldi).

La estructura operativa de represión más importante fue la Dirección de Operaciones, la que actuaba al interior del país. Para ello, el territorio fue divido en Brigadas con límites jurisdiccionales. Al norte operó la Brigada Arica-Iquique y la Brigada Coquimbo-La Serena. En la zona centro operó la Brigada Rocas de Santo Domingo. En la zona centro sur operó la Brigada Regional Sur, también conocida como Michimalongo, con asiento en Parral y una Brigada con jurisdicción en Temuco-Valdivia. Por la importancia regional y por constituirse en el enlace con la Colonia Dignidad, el cuartel de Parral (en calle Ignacio Carrera Pinto 262) se constituyó en el cuartel regional más importante después de la BIM $^{125}$.

Dentro de las brigadas orientadas a las labores de inteligencia y control, se encuentra la Brigada de Inteligencia Ciudadana. Según la inteligencia norteamericana señaló, esta Brigada civil llegó a contar en 1975 con 2100 agentes, tanto remunerados como no ${ }^{126}$ con una red cercana a los 9.000 informante. Su rol fue constituir una densa red de espionaje y delación en las diversas instituciones y dependencias del Estado, como Ministerios, Universidades y empresas públicas. Pero también en las diversas organizaciones sociales, sindicales, gremiales y en los grupos de oposición. Hacia el año 1975, el rol de esta Brigada fue controlar y vigilar todas las dependencias del Estado, hasta el punto que ningún contratación de un funcionario en el Estado podía ser materializada sin el visado de la DINA, como ratifica la Circular del Ministerio del Interior de 1975: "Su Excelencia (Pinochet) ha dispuesto que a partir de esta fecha ningún funcionario público sea contratado sin que previamente se adjunte a sus antecedentes un informe DINA respecto a las actividades que el interesado pudo haber realizado"127

Una situación similar ocurre con las Brigadas Tucapel y Ongolmo, de las que su funcionamiento y recintos aún son objeto de investigación y que al parecer poseyeron estructura de agrupación más que de brigada, al igual que la Brigada Lautaro.

Dentro de la Brigada de Inteligencia Metropolitana se reunieron dos grandes brigadas, Caupolicán y Purén, abocadas al combate del Movimiento de Izquierda Revolucionario y el Partido Socialista, respectivamente. Ambas brigadas reunieron en su interior grupos operativos que siguieron funcionando bajo a lógica de la organización compartimentada de la información y los operativos (salvo algunas excepciones de operativos conjuntos). La Brigada Purén reunión a las agrupaciones Ciervo, Alce, Leopardo, Puma y Chacal. La brigada Caupolicán, reunió a las agrupaciones Halcón I, Halcón II, Tucán, Vampiro y Águila (ver ilustración 3). Uno de los recintos que expresó con fuerza la articulación clandestina y legal durante este periodo fue el campo de Prisioneros Políticos 3 Álamos y el centro clandestino 4 Álamos, en su interior ${ }^{128}$. Siguiendo los criterios operativos de la estructura organizacional de la DINA, la compartimentación de los grupos operativos implicó que en la práctica una serie de

\footnotetext{
124 Sobre su existencia y distribuciones espaciales, véase: Informe Pericial Planimétrico N¹670/99, causa rol 2182-98.

125 Sobre la existencia del cuartel Parral, véase: Causa Rol 2182-98, "Parral”, tomo 5, foja 2 y siguiente. Causa rol 2182-98 “Álvaro Vallejos Villagrán” tomo 2a, foja 628 y siguientes. Sentencia en causa rol 28.888 (Adán Valdebenito Olavarría) del 15 de junio de 2010, p. 28. Corte de Apelaciones de Santiago, Sentencia en causa rol 2182-98 "Juan Maino" del 23 de enero de 2012 , p. 19. Declaración judicial de Ana del Carmen Lillo Gutiérrez del 20 de abril de 1992. Corte de Apelaciones de Santiago, Rol 2182-98 "Parral" tomo 5c, foja 254 y siguientes. Corte de Apelaciones de Santiago, Sentencia en causa rol 49-2004 del 15 de octubre de 2015, pp. 48-50.

126 "The 2.100 civilians (only some of wich are paid their services) constitute a subordinate unit to DINA named Brigada Inteligencia Ciudadana (Citizens Intelligence Brigade)", Department of Defense Intelligence, "Directorate of National Intelligence (DINA) Expand Operations and Facilities", 15 de abril de 1975, p.2.

127 Ministerio del Interior, Circular Reservada No 35 f-151 de 1975.

128 Comité de Cooperación para la Paz en Chile, Informe Sobre Condiciones de Vida en el Campamento Tres Álamos. Sin fecha. COPACHI. Campamento "Tres Álamos". Sección mujeres, 17 de junio de 1976.
} 
Pablo Seguel, La organización de la represión y la inteligencia en la dictadura militar chilena. Del copamiento militar del territorio al surgimiento de la Dirección de Inteligencia Nacional: Región Metropolitana, 1973-1977, Izquierdas, 49, abril 2020:767-796

brigadas y unidades especiales, con competencia en la Región Metropolitana no quedaron bajo el alero de la Brigada de Inteligencia Metropolitana. En declaración judicial, Pedro Espinoza Bravo señaló que:

Había unidades que aparecían en su desempeño visible en cuanto a sus mandos y a su ubicación en la región metropolitana, y había otras desconocidas, incluso por mí, que dependían directamente del director; me refiero al Cuerpo de Inteligencia Secreto, la unidad antisubversiva denominada Lautaro, operaciones clandestinas denominada Mulchén ${ }^{129}$.

Finalmente, el cuarto momento organizacional de la DINA se sitúa temporalmente entre los años 1975 y comienzos de 1976, cuando surge una brigada escindida de la Brigada de Inteligencia Metropolitana, dependiente directamente del Director de Inteligencia: la Brigada Lautaro ${ }^{130}$. Esta brigada de exterminio se conformó con algunos grupos operativos de las Brigadas Purén y Caupolicán, a la que se sumó el destacamento de la unidad de contrainteligencia formada por comandos de fuerzas especiales del Ejército y por el destacamento asignado al Cuartel Central de la DINA. Su centro de detención, tortura y exterminio fue el cuartel Simón Bolívar, ubicado en calle Simón Bolívar 8630, comuna de La

Ilustración 3. Estructura DINA, 1974-1977

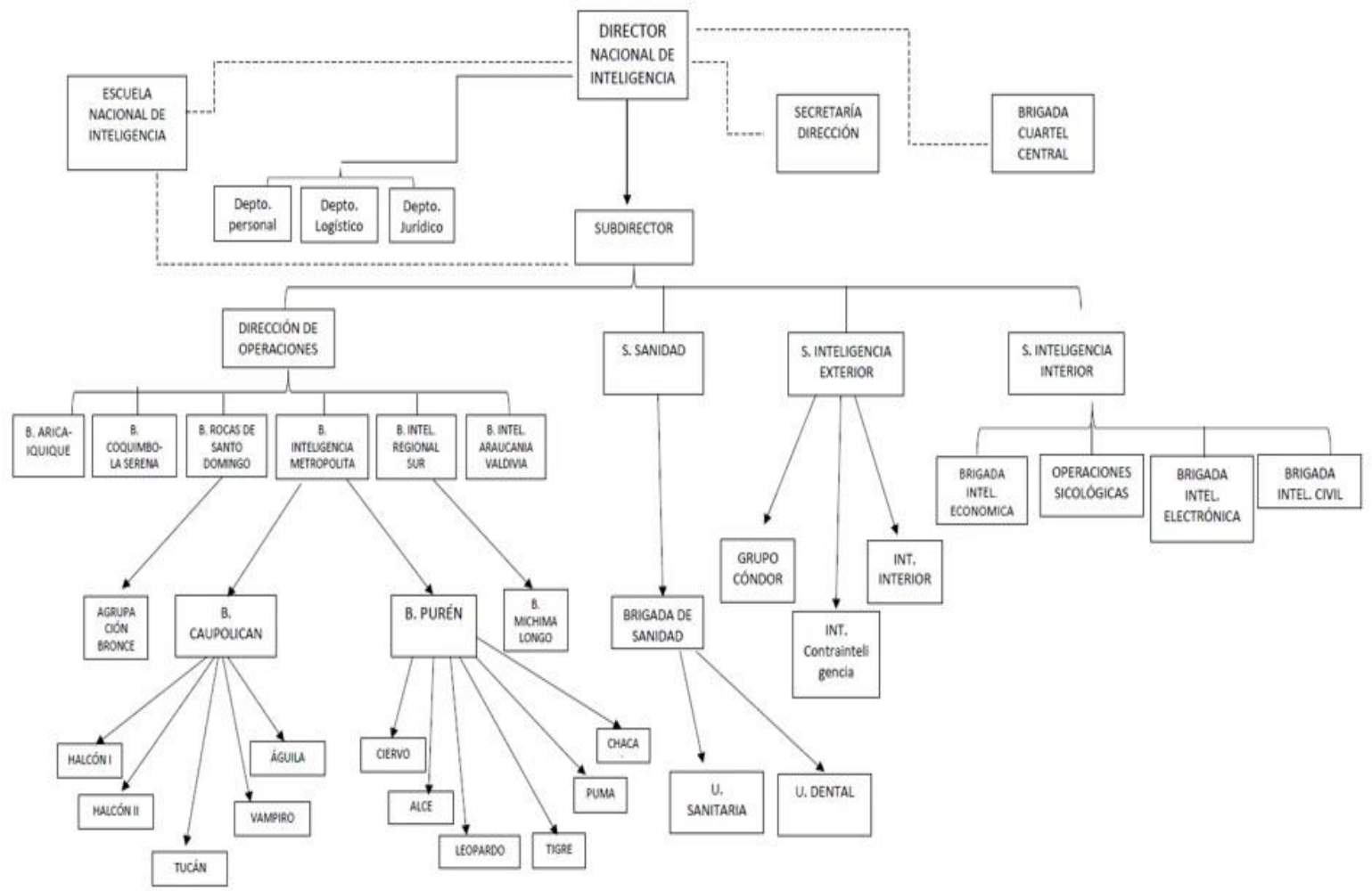

Elaboración propia en base a interpretación de declaraciones judiciales, informes policiales $y$

bibliografia especializada.

129 Declaración Judicial Pedro Espinoza Bravo del 20 de julio de 2007, causa rol 2182-98, Calle Conferencia, foja 3443 Tomo 12. Sentencia del 30 de noviembre de 2018, Causa Rol No 2182-98, Episodio "Conferencia C" o "Conferencia".

130 Sentencia del 30 de noviembre de 2018, Causa Rol No 2182-98, Episodio “Conferencia C” o “Conferencia 1”, pp. $122-124$. Hertz, Ramírez y Salazar, op. cit. Álvarez, op. cit. 
Pablo Seguel, La organización de la represión y la inteligencia en la dictadura militar chilena. Del copamiento militar del territorio al surgimiento de la Dirección de Inteligencia Nacional: Región Metropolitana, 1973-1977, Izquierdas, 49, abril 2020:767-796

Reina. Su principal objetivo se constituyó en el Partido Comunista y sus cuadros de dirección política. Su grupo operativo más importante fue el Grupo Delfín, dirigido por el capitán de Ejército German Barriga Muñoz.

\section{Balances para una aproximación al estudio de la organización de la DINA}

La emergencia de la DINA marcó una inflexión en el desarrollo de las labores represivas, el control y la inteligencia estratégicas desarrolladas con anterioridad por parte de las fuerzas armadas y policiales. Durante los primeros días del golpe de Estado la implementación de un modelo organizacional en base a los CAJSI tuvo como foco el copamiento militar del territorio, motivo por el cual a represión no se orientó con criterios de inteligencia estratégica, sino que se abocó al control del aparato de Estado, la detención masiva de los funcionarios del régimen depuesto y en contra de dirigentes sociales, sindicales y campesinos. Las labores de inteligencia al interior de las áreas jurisdiccionales fueron llevadas adelantes por los oficiales adscritos a las secciones II de Inteligencia de las diversas fuerzas armadas.

Esto repercutió en la inexistencia de criterios únicos, tanto a nivel de las mismas ramas de las fuerzas armadas, como en una misma área jurisdiccional. Para revertir esta situación y con miras a la desarticulación de las oposición política -sobre todo del Movimiento de Izquierda Revolucionaria tras su paso a la clandestinidad y a la resistencia, se implementó en noviembre de 1973 dos políticas: por una parte, se conformó la Comunidad de Inteligencia, en un intento por coordinar al SIM, la SIFA, el SIN y el SICAR en un organismo de inteligencia único y centralizado. Por otra, a través de la creación de la Comisión DINA.

Hacia enero de 1974 la dictadura militar inicia un proceso de institucionalización que la llevó a marcar simbólicamente un antes y un después desde el punto de vista de las detenciones públicas y masivas. Para ello, se crean la SENDET y se publica el Decreto Ley 228, que ajusto a legalidad las detenciones efectuadas a la fecha por las policías y las fuerzas armadas. A través de la creación de la SENDET y la constitución de su departamento de inteligencia se dispuso la generación de una fachada legal para el accionar de la Comisión DINA. Esto supuso un avance para la conformación de un servicio secreto de inteligencia política, el que será legalizado a través del Decreto $\mathrm{N}^{\circ} 521$ del 14 de junio de 1974. Esto marcará un viraje radical en el desarrollo de la organización de la represión, la cual pasará a enfocarse por criterios de inteligencia política, abocándose al combate y desarticulación de los principales blancos de la Junta Militar: el Movimiento de Izquierda Revolucionar, el Partido Socialista y el Partido Comunista.

El despliegue de una organización basada en la mantención de una cara legal, sujeta en apariencia a la legalidad autoimpuesta por la propia dictadura implicó el desarrollo de un repertorio público, mediante la labor de la SENDET. Por su parte, el desarrollo de las acciones ilegales y clandestinas, implicó en la práctica un gran desarrollo organizacional basado en agrupaciones operativas compartimentadas, reunidas en agrupaciones especializadas en blancos políticos.

Dadas las características organizacionales del servicio secreto, la estructura de la DINA estuvo constantemente sujeta a modificaciones. Esta se constituyó en una organización altamente jerárquica, compartimentada y semiclandestina que operó a lo largo del país en diversas labores de inteligencia política, control y de represión. Para ello fue dotada de amplias prerrogativas legales, que le permitieron en la práctica escindirse de todo control estatal y subordinarse directamente a las decisiones del General Augusto Pinochet Ugarte.

Para mantener el hermetismo y a su vez el control interno de los agentes, la DINA modificó constantemente sus estructuras operativas y mantuvo de manera relativamente estable los mandos funcionales de la estructura. Por ello en la cima de la organización se situó la dirección, apoyado por una brigada secreta que con posterioridad formará la Brigada Lautaro, un equipo jurídico, la subdirección, la dirección de operaciones, las subdirecciones interiores, exteriores y la de sanidad. 
Pablo Seguel, La organización de la represión y la inteligencia en la dictadura militar chilena. Del copamiento militar del territorio al surgimiento de la Dirección de Inteligencia Nacional: Región Metropolitana, 1973-1977, Izquierdas, 49, abril 2020:767-796

Sobre este mando funcional, se evidencian al menos cuatro momentos organizacionales distintos: el de la formación de las Brigadas de Interrogación y Arresto al alero de la Comisión DINA en octubre de 1973. El segundo momento que va desde su institucionalización en la SENDET hasta su legalización a través del Decreto 517 en junio de 1974. El tercero va desde la legalización de la DINA hasta la reorganización de la Brigada de Inteligencia Metropolitana hacia finales de 1975. Finalmente, el último está marcado por la reorganización del Brigada de Inteligencia Metropolitana y la creación de la Brigada Lautaro. De modo paralelo, operaron con mayores grados de autonomía y recursos la Brigada de inteligencia ciudadana y el grupo Cóndor, encargado de la implementación de la Operación Cóndor.

\section{Bibliografía.}

1. Alexander San Francisco, Miguel Fuentes y Jairo Sepúlveda, "Hacia una arqueología del Estadio Víctor Jara: campo de detención y tortura masiva de la dictadura en Chile (1973-1974)", Revista de Arqueología Histórica Argentina y Latinoamericana, No. 4, 2010, pp. 91-116

2. Ana Belén Zapata y Laura Rodríguez, "Violencia paraestatal en Mendoza y Bahía Blanca (1973-1976). Un enfoque comparativo", Clepsidra, vol.4, 2017, pp. 102-119.

3. Ariel Eidelman, "La actividad paraestatal en la Argentina a principio de los años setenta", En Débora D’Antonio (comp.), Violencia, espionaje y represión estatal, Buenos Aires: Imago Mundi, 2018, pp. 27-58.

4. Ariel Eidelman, El desarrollo de los aparatos represivos del Estado argentino durante la «Revolución Argentina», 1966-1973, Tesis doctoral, Buenos Aires, Universidad de Buenos Aires, 2010.

5. Camilo Plaza, El Servicio de Investigaciones y la Policía Política en Chile (1933-1973), manuscrito inédito, 2019.

6. Carmen Hertz, Apolonia Ramírez y Manuel Salazar, Operación exterminio. La represión contra los comunistas chilenos (1973-1976), Santiago de Chile, Lom Ediciones, 2016.

7. Central Intelligence Agency, Kubark Counterintelligence Interrogation, manuscript, July 1963.

8. Colectivo de Memoria Histórica José Domingo Cañas, Tortura en poblaciones del gran Santiago (19731990), Santiago de Chile, B\&J Impresores, 2005.

9. Comisión Nacional Sobre Prisión Política, Informe de la Comisión Nacional Sobre Prisión Política y Tortura, Santiago de Chile, 2005.

10. Corporación de Cooperación para la Paz en Chile, Descripción de las acciones de los servicios de inteligencia del gobierno militar, Feb. 1975, p. 3.

11. Cristian Gutiérrez, La Contrasubversión como política. La doctrina de guerra revolucionaria francesa y su impacto en la FF. A A. de Cbile y Argentina, Santiago de Chile, Lom Ediciones, 2018.

12. Daniel Campusano, Macarena Chinni, Constanza González y Felipe Robledo, Álvaro Corbalán: El dueño de la noche, Santiago de Chile, Ceibo Ediciones, 2015.

13. Daniel Feierstein, "la Doctrina de Seguridad Nacional en América Latina (1945-1989)", Introducción a los estudios de genocidio, Buenos Aires, Fondo de Cultura Económica, 2016, pp. 253-309.

14. Danny Monsálvez, "La historia reciente en Chile: un balance desde la nueva historia política", Historia 396, Vol. 6, no. 1, 2016, pp.111-139.

15. Dominique Monjardel, Lo que hace la policía: sociología de la fuerza pública, Buenos Aires, Prometeo, 2011.

16. Emmanuel Kahan, Unos pocos peligros sensatos. La Dirección de Inteligencia de a Provincia de Buenos Aires ante las instituciones judías de La Plata, Buenos Aires, Edulp, 2008.

17. Esteban Pontoriero, "Pensamiento militar y legislación de defensa en la Argentina: la caracterización de la amenaza a la seguridad interna ¿continuidad o ruptura? (1963-1970)", Contemporánea, vol.3, no.3, pp.149-162.

18. Eugenio Ahumada, Rodrigo Atria, Jabier Luis Egaña, Augusto Góngora, Carmen Quersney, Gustavo Saball, Gustavo Villalobos, Chile la memoria prohibida, Tomo I, II, III, Santiago de Chile, Pehuén, 1989. 
Pablo Seguel, La organización de la represión y la inteligencia en la dictadura militar chilena. Del copamiento militar del territorio al surgimiento de la Dirección de Inteligencia Nacional: Región Metropolitana, 1973-1977, Izquierdas, 49, abril 2020:767-796

19. Eva Fisher, Colaboraciones transnacionales de los Servicios de Inteligencia en el Cono Sur en los años 1970 y 1980. El papel de Brasil en el contexto de la Operación Cóndor, Santiago de Chile, Documento de Trabajo, Museo de la Memoria y los Derechos Humanos, 2015.

20. Evelyn Hevia y Jan Stehle (ed.), Colonia Dignidad: diálogos sobre verdad, justicia y memoria, Santiago de Chile, El Desconcierto, 2015.

21. Fernando Guzmán, Estadio Nacional. La sangre o la esperanza, tesis, Santiago de Chile, Pontificia Universidad Católica de Chile, 2005.

22. Florencia Levin, "Escrituras de lo cercano. Apuntes para una teoría de la historia reciente Argentina", Nuevo Mundo Mundos Nuevos, 2018.

23. Friedrich Paul Heller, Pantalones de cuero, moños... y metralletas. El trasfondo de Colonia Dignidad, Santiago de Chile: CESOC, 2007.

24. Gabriel Salazar, La violencia politica popular e las "Grandes Alamedas". La violencia en Chile 1947-1987 (una perspectiva histórico popular), Santiago de Chile, Lom Ediciones, 2006.

25. Gabriel Salazar, Villa Grimaldi (Cuartel Terranova). Vol. I. Historia, testimonio, reflexión. Santiago de Chile, Lom Ediciones, 2013.

26. Gabriela Águila, "Estudiar la represión: entre la historia, la memoria y la justicia. Problemas de conceptualización y método", Patricia Flier (comp.), Dilemas, apuestas y reflexiones teórico-metodológicas para los abordajes en Historia Reciente, La Plata, Universidad Nacional de La Plata, pp. 20-55.

27. Gabriela Águila, "La represión en la historia reciente argentina: fases, dispositivos y dinámicas regionales", Gabriela Águila y Luciano Alonso (comp.), Procesos represivos y actitudes sociales: entre la España franquista y las dictaduras del Cono Sur, Buenos Aires, Prometeo, 2013, pp. 97-121.

28. Gabriela Águila, "La represión en la Historia Reciente Argentina: perspectivas de abordaje, conceptualizaciones y matrices explicativas", Contenciosa, año 1, no. 1, pp. 2-14.

29. Gabriela Águila, "La represión en la historia reciente como objeto de estudio: problemas, novedades y derivas historiográficas", Gabriela Águila, Laura Luciani, Luciana Seminara y Cristina Viano (comps.), La historia reciente en Argentina. Balances de una historiografia pionera en América Latina, Buenos Aires, Imago Mundi, 2018, pp. 55-72.

30. Herman Schwember, Delirios e indignidad. El estéril mundo de Paul Schäfer, Santiago de Chile, J.C. Sáez Editor, 2009.

31. Hernán Merele, El proceso represivo en los años setenta constitucionales. De la depuración interna del peronismo al accionar de las organizaciones paraestatales. En: G. Águila, S. Garaño y P. Scatizza (coor.), Represión estatal y violencia paraestatal en la historia reciente Argentina, Buenos Aires, Universidad Nacional de la Plata, 2016, 99-123.

32. Igor Goicovic, "Temas y debates en la historia de la violencia política en Chile", Contenciosa, Año II, no. 3, 2014, p.17.

33. Javier Rebolledo, El despertar de los cuervos. Tejas Verdes, el origen del exterminio en Chile, Santiago de Chile, Planeta, 2016.

34. Javier Rebolledo, El despertar de los cuervos. Tejas Verdes, el origen del exterminio den Chile, Santiago, Planeta, 2016.

35. Jean-Paul Brodeaur, Las caras de la policía, Buenos Aires, Prometeo, 2011.

36. Jean-Paul Brodeur, Las caras de la policía, Buenos Aires: Prometeo, 2011.

37. Joaquín Real, Prisioneros de Guerra en Aysén, Santiago de Chile, Ediciones Kultrún, 2014.

38. Jorge Flores Durán, Londres 38 (un número desaparecido), Santiago de Chile, Editorial AUCO, 2003.

39. Jorge Magasich, Los que dijeron "No". Vol. I. Historia del movimiento de los marinos antigolpistas de 1973. Santiago de Chile, Lom Ediciones, 2008.

40. Jorge Tapia, El Terrorismo de Estado: la Doctrina de Seguridad Nacional en el Cono Sur, México D.F., Nueva Imagen-Nueva Sociedad, 1980.

41. Julio Canessa, "Introducción al Estudio de la Información Estratégica", Memorial del Ejército, año LVIII, N 324 , p. 14. 
Pablo Seguel, La organización de la represión y la inteligencia en la dictadura militar chilena. Del copamiento militar del territorio al surgimiento de la Dirección de Inteligencia Nacional: Región Metropolitana, 1973-1977, Izquierdas, 49, abril 2020:767-796

42. Julio Canessa, "Introducción al Estudio de la Información Estratégica". Memorial del Ejército, año LVIII, No 324 , pp. 14-35.

43. Julio Canessa, "Introducción al Estudio de la Información Estratégica (continuación)". Memorial del Ejército, año LVIII, $\mathrm{N}^{\circ} 325,26-36$.

44. Julio Canessa, "Introducción al Estudio de la Información Estratégica (continuación)". Memorial del Ejército, año LVIII, $\mathrm{N}^{\circ} 326$, pp. 43-52.

45. Lesley Gill, Escuela de las Américas. Entrenamiento militar, violencia politica e impunidad en las Américas, Santiago de Chile, Lom Ediciones, p. 112.

46. Lessie Jo Frazier, Salt in the sand. Memory, violence, and the nation-state in Chile, 1890 to the present, Durham y London, Duke University Press, 2007.

47. Luz Arce, El Infierno, Santiago de Chile, Tajamares Editores, 2017.

48. Magdalena Garcés, Terrorismo de Estado en Chile: la campaña de exterminio de la DINA en contra del MIR. Tesis doctoral, Salamanca, Universidad de Salamanca, 2016.

49. Manuel Ahumada, Cerro Chena. Un campo de prisioneros, Santiago de Chile, autoedición, 2011.

50. Manuel Antonio Garretón, Roberto Garretón y Carmen Garretón, Por la fuerza sin la razón: análisis de los bandos de la dictadura militar, Santiago de Chile, Lom Ediciones, 1998.

51. Manuel Contreras, La verdad histórica. El Ejército Guerrillero I, Santiago de Chile, Editorial Encina Ltda, 2000, p. 16.

52. Manuel Guerrero, "Cuando la población se hace parte de la producción social de la violencia: El caso de la colaboración mediante denuncias", Ximena Póo, La dictadura de los sumarios (1974-1985), Santiago de Chile, Editorial Universitaria, 2016, pp. 175-195.

53. Manuel Salazar, Contreras. Historia de un intocable, Santiago de Chile, Uqbar editores, 2014.

54. Manuel Salazar, Las letras del horror. Tomo I: La Dina, Santiago de Chile, Lom Ediciones, 2014.

55. Manuel Salazar, Las letras del horror. Tomo II: La CNI, Santiago de Chile, Lom Ediciones, 2014.

56. Manuel Salazar, Las letras del horror: tomo I. La DINA, Santiago de Chile, Lom Ediciones, 2011.

57. Marcelo Casals, La creación de la amenaza roja. El surgimiento del anticomunismo en Chile a la «campaña del terror» de 1964, Santiago de Chile, Lom Ediciones, 2016.

58. María José Sarrabayrouse, "El caso de la morgue judicial", Juan Pablo Bohoslavsky, (ed.). Ud. también, Doctor?" Complicidad de jueces, fiscales y abogados durante la dictadura. Buenos Aires, Siglo XXI, 2015, pp. 147-162.

59. Marina Franco y Florencia Levin, "El pasado cercano en calve historiográfica", Marina Franco y Florencia Levin (comp.), Historia reciente. Perspectivas y desafios para un campo en construcción, Buenos Aires, Paidós, 2006, pp. 31-65.

60. Marina Franco, "La historiografía del tiempo presente en el cono sur", Gabriela Águila, Laura Luciani, Luciana Seminara y Cristina Viano (comps.), La historia reciente en Argentina. Balances de una bistoriografia pionera en América Latina, Buenos Aires, Imago Mundi, 2018, pp. 175-196.

61. Marina Franco, Un enemigo para la nación. Orden Interno, violenciay "subversión", 1973-1976, Buenos Aires, Fondo de Cultura Económica, 2012.

62. Mario Amorós, "La DINA el puño de Pinochet", Ponencia presentada al $53^{\circ}$ Congreso Internacional de Americanistas, México D.F, julio de 2009.

63. Mario Garcés y Sebastián Leiva, El Golpe en la Legua, Santiago de Chile, Lom Ediciones, 2012.

64. Martin Shaw, ¿Qué es el genocidio?, Buenos Aires, Prometeo Editores, 2014.

65. Mary Helen Spooner, Soldier in a Narrow Land: The Pinochet Regimen in Chile, Berkeley, University of California Press, 1999

66. Melisa Slatman, “«En la Argentina no había escuadrones de la muerte». El dispositivo represivo argentino, la responsabilidad primaria del ejército y la planificación centralizada-ejecución descentralizada (1975-1983)", Débora D’Antonio (comp.), Violencia, espionaje y represión estatal, Buenos Aires, Imago Mundi, 2018, pp. 119-139. 
Pablo Seguel, La organización de la represión y la inteligencia en la dictadura militar chilena. Del copamiento militar del territorio al surgimiento de la Dirección de Inteligencia Nacional: Región Metropolitana, 1973-1977, Izquierdas, 49, abril 2020:767-796

67. Melissa Figueroa, Memoria abierta y para el presente. Una caracterización de la construcción de memorias en Londres 38, Santiago de Chile, 2014. América Escobar, Memoria y Materialidad. Londres 38 un estudio de caso. Tesis para optar al título profesional de antropólogo. Concepción, Universidad de Concepción, 2011.

68. Michel Bertrand y Claire Lemercier, "Introducción: ¿en qué punto se encuentra el análisis de redes en Historia?". Redes. Revisa hispana para el análisis de redes sociales, 2011, Vol. 21, 1, 1-12.

69. Miguel Lawner, La vida a pesar de todo. Isla Dawson, Ritoque, Tres Alamos, Santiago de Chile. Sergio Bitar, Isla 10, Santiago de Chile, Pehuén, 1987.

70. Mindy Cárcamo, Cristina Castillo y Yennifer Oliva, Palacio de las Sonrisas: Preservación de la Memoria Histórica de los Sucesos acaecidos en 1973 en Punta Arenas, Tesis, Punta Arenas, Universidad de Magallanes, 2013.

71. Mónica Echeverría, Krassnoff arrastrado por su destino, Santiago de Chile, Catalonia, 2011.

72. Mónica González y Héctor Contreras, Los secretos del Comando Conjunto. Santiago de Chile, Editorial Ornitorrinco, 1991.

73. Mónica González, La Conjura. Los mily un día del golpe, Santiago de Chile, Ediciones B, 2000.

74. Mónica González, La Conjura. Los mily un día del golpe, Santiago de Chile, Ediciones B, 2000,

75. Nancy Guzmán, El Fanta: historia de una traición, Santiago de Chile, Ceibo Ediciones, 2016.

76. Nancy Guzmán, Ingrid Olderock. La mujer de los perros, Santiago de Chile, Ceibo Ediciones, 2014.

77. Nancy Guzmán, Romo: Confesiones de un torturador, Santiago de Chile, Planeta, 2000.

78. Natalia Casola, "La creación de la Escuela de Inteligencia Policial Héctor Ramos. La policía política entre la dictadura y la transición democrática", Débora D'Antonio (comp.). Violencia, espionaje y represión estatal, Buenos Aires, Imago Mundi, 2018, pp. 141-163.

79. Pablo Policzer, Modelos del horror. Represión e información en Chile bajo la Dictadura Militar, Santiago de Chile, Lom Ediciones, 2014.

80. Pablo Seguel, Aproximación a las prácticas represivas y organización del Comando Conjunto a través del análisis de sus centros clandestinos de detención, tortura y exterminio. Región Metropolitana, 1975-1977, manuscrito, 2018.

81. Pascale Bonnefoy, Terrorismo de Estadio. Prisioneros de guerra en un campo de deportes, Santiago de Chile, Editorial latinoamericana, 2016.

82. Patricia Flier (comp.), Dilemas, apuestas y reflexiones teórico-metodológicas para los abordajes en Historia Reciente. La Plata, Universidad Nacional de La Plata, 2014.

83. Patricia Verdugo, Los zarpazos del puma. Caso Arellano, Santiago de Chile, CESOC / Ediciones Chile América, 1989.

84. Pedro Milos, Historia y memoria. 2 de abril de 1957, Santiago de Chile, Lom Ediciones, 2007.

85. Pilar Calveiro, Poder y desaparición. Los campos de concentración en Argentina, Buenos Aires, Coligüe, 2014.

86. Rolando Álvarez, Desde las sombras: una historia de la clandestinidad comunista (1973-1980), Santiago de Chile, Lom Ediciones, 2003.

87. Romina Ampuero, Recinto DIN A clínica Santa Lucia. Dossier de Investigación, manuscrito, 2018. Guzmán, op. cit.

88. Sady Arenas, La sorda justicia. El "Hoyo" de José Domingo Cañas, Cuartel Ollägue de la DINA, Santiago de Chile, Fundación José Domingo Cañas, 2016.

89. San Francisco Alejandro (ed.), La Academia de Guerra del Ejército de Chile, 1886-2006, Santiago de Chile, Centro de Bicentenario, 2006.

90. Santiago Garaño, "Pabellones de la muerte: los límites difusos entre la represión legal y la clandestina", Revista Entrepasados, 34, pp. 33-53.

91. Sebastián Leiva, "La represión que no importó. La violencia estatal contra los delincuentes comunes tras el golpe de estado de 1973", Ernesto Bohoslavsky, Marina Franco, Mariana Iglesias y Daniel Lvovich (comps.), Problemas de Historia Reciente del Cono Sur, Buenos Aires, Prometeo Libros/UNGS, 2011, pp. 99- 124.

92. Ulrick Brandes, Patrick Kenis y Jörg Raab, "La explicación a través de la visualización de redes". Redes. Revista hispana para el análisis de redes sociales, 2005, Vol. 9, 1, 1-11. 
Pablo Seguel, La organización de la represión y la inteligencia en la dictadura militar chilena. Del copamiento militar del territorio al surgimiento de la Dirección de Inteligencia Nacional: Región Metropolitana, 1973-1977, Izquierdas, 49, abril 2020:767-796

93. Varios Autores, Archivo y memorias de la represión en América Latina (1973-1990), Santiago de Chile, Lom Ediciones, 2015.

94. Varios autores, El batallón de inteligencia 601, Buenos Aires, Programa Verdad y Justicia Ministerio de Justicia y Derechos Humanos, 2015.

95. Verónica Valdivia, "Chile: ¿un país de «excepción»? La Ley de Control de Armas y la máquina represiva puesta en marcha, Julio Pinto (coor. y ed.), Cuando hicimos historia. La experiencia de la Unidad Popular, Santiago de Chile, Lom Ediciones, 2014, pp. 205-232.

96. Verónica Valdivia, "Estamos en Guerra Señores. El Régimen Militar de Pinochet y el Pueblo, 19731980", Historia, 43, vol. I, pp. 163-201.

97. Verónica Valdivia, "Todos juntos seremos la historia: Venceremos" Unidad Popular y fuerzas Armadas", Julio Pinto (coor. y ed.), Cuando hicimos historia. La experiencia de la Unidad Popular, Santiago de Chile, Lom Ediciones, 2017, pp. 177-206.

98. Verónica Valdivia, El golpe después del golpe. Leigh vs. Pinochet. Chile, 1960-1980, Santiago de Chile, Lom Ediciones, 2003.

99. Verónica Valdivia, Subversión, coerción y consenso. Creando el Chile del siglo XX (1918-1938), Santiago de Chile, Lom Ediciones, 2017.

100.Wolgang Sofsky, La organización del terror. Los campos de prisioneros, Buenos Aires, Prometeo, 2016. 